\title{
PARÂMETROS BIOQUÍMICOS FOLIARES DAS ESPÉCIES Licania tomentosa (BENTH.) E Bauhinia forficata (LINK.) PARA AVALIAÇÃO DA QUALIDADE DO AR
}

\author{
Otávio Luiz Gusso Maioli*, Jane Meri Santos, Neyval Costa Reis Júnior e Sérvio Túlio Alves Cassini \\ Departamento de Engenharia Ambiental, Universidade Federal do Espírito Santo, 29075-910 Vitória - ES, Brasil
}

Recebido em 2/5/07; aceito em 2/6/08; publicado na web em 10/11/08

\begin{abstract}
FOLIAR ANALYSES OF BIOCHEMICAL PARAMETERS OF Licania tomentosa (BENTH.) AND Bauhinia forficata (LINK.) SPECIES FOR AIR QUALITY ASSESSMENT. Foliar analysis of biochemical parameters were carried out in order to investigate the influence of air pollutants on two tropical tree species (Licania tomentosa (Benth.) and Bauhinia forfícata (Link.)). Special attention was given to tropospheric ozone due to the fact that concentration levels in the region were found to be up to $140 \mu \mathrm{g} \mathrm{m}^{-3}$ for a $4 \mathrm{~h}$ average time, which is well above the value that can cause injuries to orchides and tobacco $\left(59 \mu \mathrm{g} \mathrm{m}^{-3}\right)$. Other pollutants such as nitrogen and sulphur oxides were measured and their ambient concentrations were also associated to biochemical alterations in the investigated species.
\end{abstract}

Keywords: biochemists parameters; passive biomonitoring; air pollution.

\section{INTRODUÇÃO}

Os vegetais absorvem os gases da atmosfera através dos estômatos durante os processos de respiração e fotossíntese. Os gases poluentes também são absorvidos, causando alterações no meio foliar. Os óxidos de nitrogênio $\left(\mathrm{NO}, \mathrm{NO}_{2}\right)$, óxidos de enxofre $\left(\mathrm{SO}, \mathrm{SO}_{2}, \mathrm{SO}_{3}\right)$ e ozônio $\left(\mathrm{O}_{3}\right)$, dentre outros, provocam danos em determinadas espécies arbóreas como alteração no crescimento, no metabolismo e injúria nas folhagens. A poluição do ar pode provocar alterações fisiológicas, bioquímicas, anatômicas e comportamentais que podem ser associadas à presença de poluentes atmosféricos. Desse modo, respostas bioquímicas vegetais fora do padrão natural podem auxiliar na avaliação da qualidade do ar de determinadas regiões.

Bussoti e Ferreti ${ }^{2}$ avaliaram a relação entre a poluição do ar e a destruição de florestas no sul da Europa e verificaram o grau de desfolhamento das árvores através de experimentos com mudas expostas a elevadas concentrações de poluentes. Desse estudo, concluiu-se que o ozônio é o principal contaminante que provoca necroses nas folhas da vegetação presente nas florestas, apesar da discussão apresentada pelos autores sobre a necessidade de estudos mais aprofundados sobre os critérios utilizados para determinar o declínio das florestas no sul da Europa. Agrios ${ }^{3}$ também observou injúrias agudas, na forma de necrose branca, nas folhas da espécie vegetal Disporum hookeri, causadas pelas altas concentrações de $\mathrm{SO}_{2}$ em British Columbia, Canadá.

As espécies Astrantia major, Centuarea nigra, Centauria scabiosa, Humex acetosa, Sambucus racemosa e Humulus lupulus foram investigadas por Manning e Godizic ${ }^{4}$ em países da Europa Central e Oriental e mostraram-se sensíveis ao ozônio. A análise da progressão dos sintomas decorrentes da exposição, tais como bronzeamento das folhas, necroses e cloroses, comprovou esta sensibilidade. Estas espécies foram submetidas a concentrações de 60 a 80 ppb durante $7 \mathrm{~h}$ por dia no decorrer de uma semana, onde foram verificados os estágios de danos foliares. Centaurea nigra apresentou cerca de $80 \%$ de sua superfície foliar danificada.

Sonchus oleraceus e Medicago sativa, espécies nativas do Egito, foram submetidas a concentrações de 50 e $100 \mathrm{ppb}$ em $5 \mathrm{~h}$ por dia

*e-mail: otaviomaioli@iq.ufrj.br durante 5 dias consecutivos, através de um experimento controlado realizado por El-Khatib, ${ }^{5}$ para excluir outras variáveis, tais como intensidade de luz, nutrientes do solo e disponibilidade de água. Dentre os parâmetros bioquímicos analisados destacaram-se clorofila A e B, $\beta$-caroteno e ácido ascórbico, que são componentes consumidos na presença do ozônio para estas espécies.

O estudo da resposta de um organismo à poluição ambiental é denominado bioindicação. Trabalhos desenvolvidos no Brasil concluíram que plantas como o feijoeiro (Phaseolus vulgaris), ${ }^{6}$ a tradescantia $(\text { Tradescantia pallida) })^{7}$ e o tabaco (Nicotina tabacum $)^{8}$ podem ser empregados, com sucesso, na avaliação da qualidade ambiental de áreas sob influência de emissões atmosféricas de poluentes, especialmente ozônio. ${ }^{9} \mathrm{O}$ uso de vegetais como ferramenta na avaliação da qualidade do ar fornece respostas de sistemas biológicos de modo integrado, ou seja, a ação de vários poluentes ao mesmo tempo e em condições atmosféricas reais. Entretanto, outras variáveis dificultam o estudo, como idade da planta, efeitos da luz, umidade, temperatura, composição dos solos e alterações dos sistemas enzimáticos. Desse modo, torna-se importante o isolamento destas variáveis através da padronização da metodologia adotada na medição dos parâmetros bioquímicos indicadores de poluição atmosférica.

De acordo com Stern, ${ }^{1}$ a concentração mínima de ozônio capaz de causar alterações visíveis em vegetais, como tabaco, legumes e orquídeas, é de $59 \mu \mathrm{g} \mathrm{m}^{-3}$ para um tempo de exposição de $4 \mathrm{~h}$. Esta concentração é ultrapassada várias vezes na Região da Grande Vitória (RGV), alcançando picos de até $140 \mu \mathrm{g} \mathrm{m}^{-3}$. Para $\mathrm{NO}_{2}$, estas concentrações mínimas são de $4700 \mu \mathrm{g} \mathrm{m}^{-3}$ para o mesmo tempo de exposição ao ozônio, enquanto que para $\mathrm{SO}_{2}$, são de $785 \mu \mathrm{g} \mathrm{m}^{-3}$ para um tempo de exposição de $8 \mathrm{~h}$. Para os tempos de exposição relatados, as concentrações de $\mathrm{NO}_{2}$ e de $\mathrm{SO}_{2}$ raramente ultrapassam 160 e 70

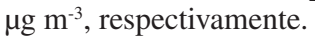

O ozônio, quando absorvido para o meio intercelular através dos estômatos, é convertido a espécies oxigenadas ativas (active oxigen species - AOS), tais como $\mathrm{O}_{2}^{\cdot-}, \mathrm{HO} \cdot \mathrm{e}_{2} \mathrm{O}_{2}$. Uma vez produzidos estas AOS na planta, estas interferem direta e indiretamente em compostos com potenciais redutores como, por exemplo, ácido ascórbico e $\beta$-caroteno. Além disso, AOS podem reagir com a membrana lipídica para a produção de peroxidases. ${ }^{10}$ Sendo assim, o ozônio pode ser responsável pelo impacto sobre a vegetação em algumas localidades 
na Região da Grande Vitória, onde as concentrações de ozônio são conhecidas devido à existência de equipamento de monitoramento da qualidade do ar.

A determinação dos parâmetros bioquímicos foliares, tais como $\mathrm{pH}$, capacidade de tamponamento (BCI), ácido ascórbico, atividade enzimática de peroxidase, clorofila A e B, e $\beta$-caroteno, pode identificar o nível de estresse da planta. Determinados contaminantes em certos valores de concentração causam variações relevantes destes parâmetros, dependendo do intervalo de tempo de exposição. ${ }^{11}$ As espécies estudadas foram Licania tomentosa e Bauhinia forficata, as quais estão presentes na mata secundária da RGV. A influência do solo também foi avaliada neste trabalho.

\section{PARTE EXPERIMENTAL}

\section{Espécies e locais escolhidos}

As espécies escolhidas foram a Licania tomentosa, de nome popular oiti, e a Bauhinia forficata, de nome popular pata-de-vaca. A escolha destas espécies baseou-se nos critérios apresentados por Wittig. ${ }^{12}$ Foram escolhidos três indivíduos de cada espécie aleatoriamente, a uma distância inferior a $500 \mathrm{~m}$ de três estações de monitoramento da qualidade do ar da Grande Vitória que estão representadas na Figura 1: Enseada do Suá, em Vitória (ENS); Laranjeiras, na Serra (LAR); e Ibes, em Vila Velha (IBV). Outro local analisado foi a Reserva Biológica de Duas Bocas em Cariacica (RDB), que foi escolhida como local de referência, pois os resultados de modelos matemáticos de dispersão atmosférica, obtidos por Silveira, ${ }^{13}$ mostram que as concentrações de $\mathrm{NO}_{x}$ nesta Reserva Biológica são muito menores que as observadas nas estações de monitoramento.

Foram realizadas três campanhas de coletas: $1^{\mathrm{a}}$ campanha $(\mathrm{C} 1)$ nos dias 3 de outubro e 4 de novembro de 2003 (campanha conjunta, pois não foram observadas diferenças dos parâmetros bioquímicos entre estes meses), $2^{\mathrm{a}}$ campanha (C2) no dia 18 de dezembro de 2004 e $3^{\text {a }}$ campanha (C3) no dia 4 de agosto de 2005. Estas campanhas foram realizadas nestes períodos com o intuito de analisar a variação anual e sazonal dos parâmetros bioquímicos.

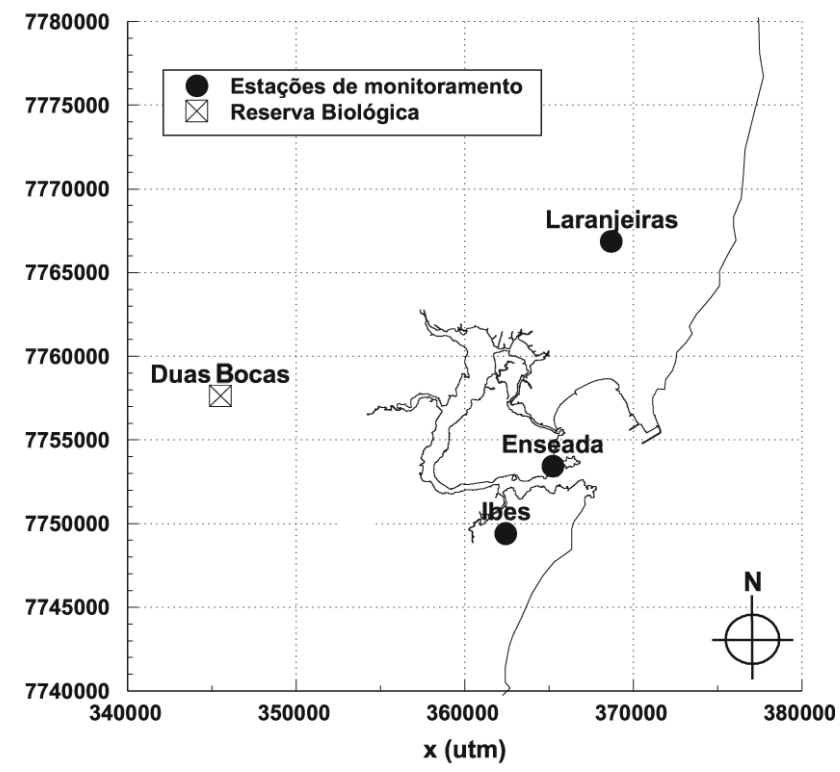

Figura 1. Localização das estações de monitoramento e Reserva Biológica de Duas Bocas (RGV)

\section{Determinação dos nutrientes do solo}

Foram avaliados $\mathrm{pH}$, fósforo, potássio, cálcio, magnésio, alumínio, acidez potencial $(\mathrm{H}+\mathrm{Al})$, soma de bases, capacidade de troca catiônica (Ctc), saturação das bases (V) e matéria orgânica. A determinação destes parâmetros seguiu a metodologia aplicada pela EMBRAPA. ${ }^{14} \mathrm{~A}$ análise de solo foi realizada uma única vez em dezembro de 2003.

\section{Determinação das concentrações de $\mathrm{PM}_{10}, \mathrm{SO}_{2}$ e $\mathrm{NO}_{2}$}

Foram determinadas as médias diárias das concentrações horárias das partículas menores que $10 \mu \mathrm{m}\left(\mathrm{PM}_{10}\right)$, as médias diárias das concentrações horárias de $\mathrm{SO}_{2}$ e as médias horárias das concentrações $\mathrm{NO}_{2}$. As metodologias aplicadas para $\mathrm{PM}_{10}, \mathrm{SO}_{2}$ e $\mathrm{NO}_{2}$ são as mesmas adotadas para determinação dos padrões primários e secundários estabelecidos pela Resolução CONAMA.${ }^{15} \mathrm{O}$ padrão primário de qualidade do ar está relacionado às concentrações de poluentes presentes no ar que, se ultrapassadas, poderão afetar a saúde humana. O padrão secundário da qualidade do ar representa o nível de contaminação do ar em que se prevê o mínimo dano à fauna, à flora, aos materiais e ao meio ambiente em geral, assim como o mínimo efeito adverso sobre o bem-estar da população.

\section{Determinação das concentrações de ozônio}

As metodologias utilizadas na determinação das concentrações de ozônio são citadas no Ozone Biomonitoring Program, ${ }^{16}$ que monitora a qualidade do ar para utilização de indicadores naturais. As metodologias aplicadas foram SUM 0, SUM 60, AOT-40 e média móvel para 4 h de exposição. SUM 0 é a soma diária de todas as concentrações horárias de ozônio medidas em ppb. SUM 60 é a soma de todas as concentrações horárias de ozônio que se igualam ou que excedem a 60 ppb. AOT-40 é um método que consiste no somatório das concentrações acumuladas, com valores acima de $40 \mathrm{ppb} \mathrm{h}^{-1} .^{17}$ Média móvel para $4 \mathrm{~h}$ de exposição é a média realizada para um conjunto de 4 tempos horários de exposição, com deslocamento de horário para este conjunto.

Os dados horários das concentrações de ozônio, $\mathrm{PM}_{10}, \mathrm{SO}_{2}$ e $\mathrm{NO}_{2}$ são fornecidos pelo IEMA, através da rede automática de monitoramento da qualidade do ar da Grande Vitória.

\section{Coleta das folhas}

De cada árvore dos três indivíduos de cada espécie em cada local, amostras de folhas foram retiradas dos ramos mais externos, mais expostos aos poluentes aéreos e à radiação solar, tomando-se cuidado em descartar folhas envelhecidas ou jovens. As folhas foram cortadas juntamente com o auxílio de um podão em altura padronizada. Ainda em campo, as folhas coletadas foram colocadas em sacos plásticos devidamente numerados, conservadas em isopor com gelo, e imediatamente levadas para laboratório, onde foram lavadas com água deionizada e secas ao ar livre, pois as metodologias utilizam folhas frescas em suas análises. As folhas foram coletadas entre 8 e $10 \mathrm{~h}$ da manhã. Os dias das coletas foram realizados após 7 ou mais dias de ausência de chuvas. Das folhas analisadas, foram retirados apenas o tecido foliar, eliminando-se o pecíolo nas triturações para preparação dos extratos foliares. ${ }^{18}$

\section{Determinação dos parâmetros bioquímicos nas folhagens}

Para a medida da concentração de $\mathrm{H}^{+}$e da capacidade de tamponamento da acidez (Buffer Index Capacity - BCI), 0,500 g de tecido foliar foram homogeneizados e moídos em $60 \mathrm{~mL}$ de água destilada. $\mathrm{O}$ 
$\mathrm{pH}$ inicial foi medido com um aparelho eletrônico medidor de $\mathrm{pH}$ calibrado (Onda Científica LTDA, modelo TCP01, série: 5536/212). Em seguida adicionou-se um certo volume de ácido $\left(\mathrm{HCl} \mathrm{0,02} \mathrm{mol} \mathrm{L}^{-1}\right)$ necessário para promover a mudança de cerca de 1,0 unidade de pH. O BCI foi calculado com base no peso da folha fresca, usando a Equação de Pylypec e Redmann, ${ }^{19}$ modificada por Bender. ${ }^{20} \mathrm{O} \mathrm{BCI}$ foi definido como a relação entre $\mathrm{H}^{+}$adicionada (volume em $\mathrm{mL}$ de $0,02 \mathrm{~mol} \mathrm{~L}^{-1} \mathrm{HCl}$ ) e a mudança produzida em concentração de $\mathrm{H}^{+}$no homogenado, em $\mu \mathrm{mol} \mathrm{L} \mathrm{L}^{-1}$.

O conteúdo de ácido ascórbico de folhagens foi determinado pelo método colorimétrico do 2,6-diclorofenol-indofenol ligeiramente modificado (DIP)-método, descrito por Freebairn. ${ }^{21} \mathrm{O}$ método descrito é específico para ácido ascórbico em extrato de folhas frescas. Inicialmente são preparadas duas soluções para esta análise: a "solução de inibição" e a "solução de corante". A solução de inibição contém $5,00 \mathrm{~g}$ de ácido oxálico (98,5\%, Merck) e 0,75 g de Na-EDTA (99\%, Merck, EUA), aferido para balão de $1000,0 \mathrm{~mL}$ com água destilada para inibir a oxidação de ácido ascórbico através de metais pesados. ${ }^{22}$ A solução de corante é preparada dissolvendo $100 \mathrm{mg}$ do sal de $\mathrm{Na}$ de 2,6-diclorofenol-indofenol (99,5\%:Sigma EUA) aferido para balão de 500,0 $\mathrm{mL}$ com água destilada $\left(80^{\circ} \mathrm{C}\right)$. Depois de esfriar, dilui-se a $1000,0 \mathrm{~mL}$ com água destilada. Esta solução é mantida na geladeira durante uma semana $\left(2-5^{\circ} \mathrm{C}\right)$. São homogeneizados cerca de $0,500 \mathrm{~g}$ de folhagem fresca em 20,0 mL de uma solução denominada solução de inibição. Em um cadinho, as folhas são moídas e misturadas com a "solução de inibição". Leva-se a mistura para uma centrífuga de $4 \mathrm{~g}$ durante 30 min. O pellet é descartado e tem-se, então, a solução do extrato da folha. Para a determinação colorimétrica, $1,0 \mathrm{~mL}$ da solução do extrato da folha são misturados a 7,0 mL de uma solução conhecida como "solução de corante", onde são vigorosamente misturadas. Utilizando um espectrofotômetro (Hach, modelo DR/2000), fazem-se as leituras de absorbância em $\lambda=520 \mathrm{~nm}$. Após a primeira leitura, 1,00 mL de solução 1\% de ácido ascórbico (99,5\%, Merck) é adicionada para alvejar a tintura e nova leitura é efetuada. Como espaço em branco para as leituras no espectrofotômetro, utilizou-se a "solução de inibição" e a "solução corante", que são misturadas e medidas. O conteúdo de ácido ascórbico é estimado a partir da diferença entre essas leituras. Uma curva de calibração contendo diferentes concentrações conhecidas de ácido ascórbico é feita e a partir dela se encontra a concentração de ácido ascórbico utilizando a diferença entre as leituras descritas anteriormente.

Para determinação da atividade das peroxidases não específica, $0,500 \mathrm{~g}$ de uma amostra de folhagem foi macerada em tampão fosfato $0,1 \mathrm{~mol} \mathrm{~L}^{-1}$, pH $6(20,0 \mathrm{~mL})$. Este extrato é submetido a uma vigorosa agitação durante 5 min. Após centrifugação (10 g, 30 min) coletou-se o sobrenadante para medição da atividade das peroxidases, à temperatura ambiente. A seguir, prepara-se uma mistura reacional para a medição utilizando espectrofotômetro (Hach, modelo DR/2000). O volume total desta mistura reacional é de $6,5 \mathrm{~mL}$ constituída por: $2 \mathrm{~mL}$ de tampão fosfato $\left(0,1 \mathrm{~mol} \mathrm{~L}^{-1}, \mathrm{pH}\right.$ 6), $2 \mathrm{~mL}$ de peróxido de hidrogênio (PA 32\%; Merck) $3 \mathrm{mmol} \mathrm{L}^{-1}, 2,0 \mathrm{~mL}$ de guaiacol (2-metoxifenol, PA, Merck) $15 \mathrm{mmol} \mathrm{L}^{-1}$ e por $0,50 \mathrm{~mL}$ do extrato enzimático. $\mathrm{O}$ espectrofotômetro mede a absorbância do tetraguaiacol $(470 \mathrm{~nm})$, que á formado pela reação entre $\mathrm{H}_{2} \mathrm{O}_{2}$ e o guaiacol, sendo a leitura efetuada de $15 \mathrm{em} 15 \mathrm{~s}$, decorridos 2 min. Com estes valores, foi construída uma curva de calibração para cada medição, determinando-se a atividade das peroxidases considerando o coeficiente de extinção molar $(\varepsilon)$ do tetrahidroguaiacol igual a 26,6 $\mathrm{mmol}^{-1} \mathrm{~cm}^{-1}$. Este método é descrito por Kim e Yoo. ${ }^{23}$

A determinação de clorofilas A e B, clorofila total, clorofila A/B e $\beta$-caroteno é realizada a partir de método espectrofotométrico. A partir de 1,000 $\mathrm{g}$ de folhagem fresca, foram a elas adicionadas 20 $\mathrm{mL}$ de solução de Acetona $90 \%$ (PA; Merck), para extração das clorofilas e $\beta$-caroteno. A mistura foi triturada durante cinco minutos e logo depois centrifugada durante $30 \mathrm{~min}$ em centrifuga de $4 \mathrm{~g}$. Foi separado então o sobrenadante e levado para análise espectrométrica (espectrofotômetro Hach, modelo DR/2000). Para cada extrato, foram medidas as leituras das absorbâncias (Abs) em 480, 647, 664 e 750 $\mathrm{nm}$. Os valores de absorbâncias das equações são todos descontados dos valores de $750 \mathrm{~nm}$. Para determinação das clorofilas, foram utilizadas as Equações propostas por Jeffrey e Humphrey. ${ }^{24}$ A soma das clorofilas A e B resulta no conteúdo de clorofilas totais. A relação clorofila $\mathrm{A} / \mathrm{B}$, também é um parâmetro analisado. Para determinação do $\beta$-caroteno, utiliza-se a Equação de Kirk e Allen. ${ }^{25}$

Os dados foram submetidos a uma análise de variância (ANOVA) e, quando os valores do teste Fisher (F) foram significativos, comparações das médias entre os locais foram realizadas usando o teste Tukey, ao nível de significância de 10\%, para cada campanha e para cada espécie. Este mesmo tratamento foi feito para verificar diferenças dos parâmetros bioquímicos entre as campanhas para cada espécie.

\section{RESULTADOS E DISCUSSÃO}

\section{Qualidade do solo dos locais monitorados}

A qualidade do solo foi diagnosticada através do resultado da análise de solo dos locais de estudo (Tabela 1). Os parâmetros do solo analisados informam sobre as condições nutricionais às quais as plantas estão dispostas. Estes parâmetros foram qualificados de acordo com a EMBRAPA. ${ }^{14}$

Tabela 1. Concentração dos nutrientes do solo dos locais de estudo

\begin{tabular}{|c|c|c|c|c|}
\hline$\underline{\text { Parâmetros }}$ & Duas Bocas (RDB) & Enseada do Suá (ENS) & Ibes (IBV) & Laranjeiras (LAR) \\
\hline $\mathrm{pH}\left(\mathrm{H}_{2} \mathrm{O}\right)$ & 5,80 & 4,92 & 5,99 & 5,38 \\
\hline Fósforo $(\mathrm{P})^{*}$ & 14,03 & 2,89 & 5,11 & 5,94 \\
\hline Potássio $(\mathrm{K})^{*}$ & 157,80 & 68,60 & 91,50 & 58,10 \\
\hline Cálcio $(\mathrm{Ca})^{*}$ & 3,28 & 4,50 & 2,41 & 2,44 \\
\hline Magnésio $(\mathrm{Mg}) * *$ & 1,20 & 0,43 & 0,95 & 0,10 \\
\hline Alumínio (Al)** & 2,09 & 1,27 & 0,26 & 0,70 \\
\hline Acidez potencial $(\mathrm{H}+\mathrm{Al})^{* *}$ & 2,15 & 5,86 & 3,70 & 2,06 \\
\hline Soma de bases $(\mathrm{S})^{* *}$ & 5,14 & 0,35 & 1,46 & 3,76 \\
\hline Capacidade troca de cátions $(\mathrm{Ctc})^{* *}$ & 4,92 & 5,16 & 4,66 & 2,92 \\
\hline Saturação de Bases (V)*** & 61,91 & 68,12 & 39,11 & 32,97 \\
\hline Matéria orgânica**** & 5,78 & 3,76 & 2,68 & 1,10 \\
\hline
\end{tabular}

* $\mathrm{mg} \mathrm{dm}^{-3} ; * * \mathrm{cmolc} \mathrm{dm}^{-3}=1.10^{-2} \mathrm{~mol} \mathrm{~m}^{-3}$ (Na análise de solo, é a concentração disponível para a absorção pelas plantas); ***percentagem (\%); ****1 dag $\mathrm{m}^{-3}=1.10^{4} \mathrm{mg} \mathrm{m}^{-3}$. 
Solos alcalinos apresentam alguns cátions precipitados, e elementos como ferro, manganês, cobre e zinco podem tornar-se indisponíveis para as plantas. ${ }^{26}$ Entretanto, os solos estudados são todos ácidos, o que disponibiliza estes elementos para as plantas. O solo da estação da ENS apresentou a mais alta acidez. Os outros locais são constituídos de solos com média acidez. O teor de fósforo $(\mathrm{P})$ no solo das estações se mostrou baixo, enquanto que em RDB foi normal, sendo quase três vezes maior. $\mathrm{O}$ fósforo aumenta a resistência da planta a doenças, pois eleva a maturação dos tecidos. ${ }^{27} \mathrm{O}$ potássio $(\mathrm{K})$ apresentou alta concentração no solo de RDB e baixa concentração na ENS e LAR. O teor de cálcio foi alto na ENS e médio nos outros locais. A deficiência de potássio retarda a cicatrização de injúrias, favorecendo a entrada de fungos e poluentes. ${ }^{28} \mathrm{O}$ cálcio (Ca), além de grande regulador da acidez do solo, fornece estabilidade às paredes celulares, favorecendo o crescimento das espécies vegetais. ${ }^{29} \mathrm{~A}$ concentração de magnésio $(\mathrm{Mg})$ foi alta em RDB e baixa na ENS e LAR. LAR apresentou teor de magnésio doze vezes menor que RDB, enquanto que em ENS foi três vezes menor. O magnésio é um dos componentes da clorofila e sua deficiência no solo pode comprometer o processo de fotossíntese. A concentração de alumínio (Al) foi alta na ENS em RDB e baixa no IBV, sendo neste local dez vezes menor que em RDB. A análise de alumínio (Al) indica a quantidade de alumínio que poderá entrar em contato com as raízes das plantas. A alta concentração de alumínio no solo pode apresentar considerável toxicidade para a planta, podendo, juntamente com um meio ácido, causar injúrias nas folhas. A acidez potencial foi baixa em LAR e RDB e alta na ENS, comportamento este semelhante à acidez do solo. A acidez potencial refere-se ao total de $\mathrm{H}^{+}$em ligação covalente mais $\mathrm{H}^{+}$e $\mathrm{Al}^{3+}$ trocáveis, ou seja, o quanto de $\mathrm{H}^{+}$estaria disponível para ser liberado no solo.

A capacidade de troca catiônica (Ctc) apresentou-se baixa apenas em LAR, e não houve problema nos outros locais. A Ctc fornece informações sobre a quantidade de cátions ( $\mathrm{Al}, \mathrm{H}, \mathrm{Ca}, \mathrm{Mg}$ e $\mathrm{K}$ ) que o solo consegue reter, sendo dependente do $\mathrm{pH}$ do meio. A proporção desta Ctc, que é ocupada por bases, é o parâmetro denominado Saturação de Bases (V). Os solos de LAR e IBV apresentaram baixa saturação de bases, enquanto que na ENS e em RDB este parâmetro apresentou valor médio e semelhante. Quanto maior o valor de V, mais fértil será o solo. Outro parâmetro de solo medido foi a Soma de Bases, que consiste na soma dos teores de $\mathrm{Ca}, \mathrm{Mg}$ e $\mathrm{K}$. A Soma de Bases foi baixa para IBV e ENS, onde nesta apresentou um valor cerca de 15 vezes menor que em RDB. A baixa concentração desses três importantes elementos combinados indica infertilidade do solo. Os teores de nitrogênio podem ser determinados a partir da quantidade de matéria orgânica presente no solo. LAR apresentou concentração baixa de matéria orgânica, enquanto que em RDB a concentração foi alta, e nos outros locais, valores médios. $\mathrm{O}$ maior teor de nitrogênio no solo, que ocorre em solos com maiores teores de matéria orgânica, aumenta o teor de clorofila em plantas de determinadas espécies, como a batata, por exemplo. A matéria orgânica presente no solo tem um importante papel na manutenção da boa qualidade do solo. Exerce benefícios no suprimento de nutrientes para as plantas, na estrutura da planta, na boa compactação do solo e na capacidade de retenção de água. ${ }^{30}$

\section{Análise das concentrações de $\mathrm{PM}_{10}, \mathrm{SO}_{2}$ e $\mathrm{NO}_{2}$}

As partículas menores que $10 \mu \mathrm{m}\left(\mathrm{PM}_{10}\right)$ apresentaram concentrações médias diárias entre 20 e $40 \mu \mathrm{g} \mathrm{m}^{-3}$, com picos ocasionais entre 60 e $80 \mu \mathrm{g} \mathrm{m}^{-3}$, principalmente em LAR (Figura 2). As Figuras $1 \mathrm{~S}$ e $2 \mathrm{~S}$ (Material Suplementar) apresentam as concentrações médias diárias de $\mathrm{PM}_{10}$ na ENS e no IBV, respectivamente. Em nenhuma das estações os valores de $\mathrm{PM}_{10}$ ultrapassaram $150 \mu \mathrm{g} \mathrm{m}^{-3}$ (padrões primário e secundário ${ }^{15}$ ).

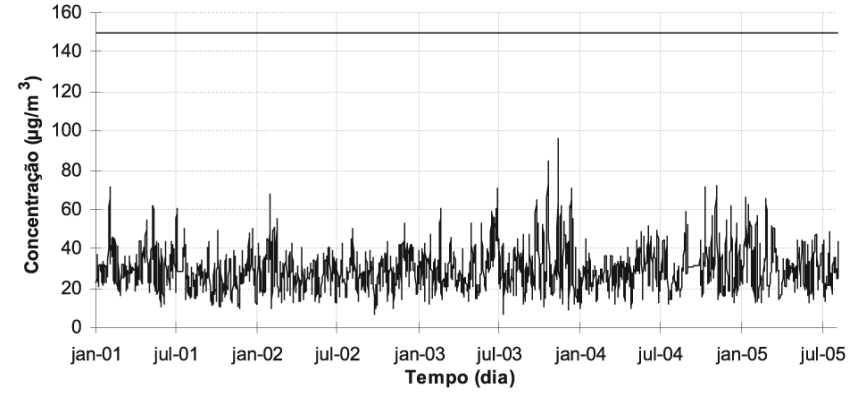

Figura 2. Médias diárias das concentrações horárias de PM 10 em Laranjeiras.

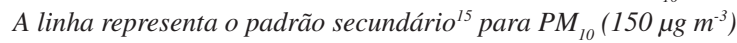

Os valores da média diária para $\mathrm{SO}_{2}$ apresentaram grandes variações para os períodos anteriores e posteriores a janeiro de 2004 na estação de LAR (Figura 3), indicando provável imprecisão do aparelho de medição para este período. A estação da ENS (Figura 3S) apresentou os maiores picos, com grande número de valores registrados entre 20 e $30 \mu \mathrm{g} \mathrm{m}^{-3}$. Na estação do IBV foi grande o número de dados invalidados (Figura 4S), onde houve um período de cerca de 6 meses sem medições, entre 2004 e 2005. Para os dados a partir de 2004, os valores das médias diárias não ultrapassaram $30 \mu \mathrm{g} \mathrm{m}^{-3}$ nas estações, e freqüentemente se encontraram entre 10 e $20 \mu \mathrm{g} \mathrm{m}^{-3}$. Estas concentrações médias diárias estão bem abaixo dos padrões primários e secundários que são de 365 e $100 \mu \mathrm{g} \mathrm{m}^{-3}$, respectivamente.

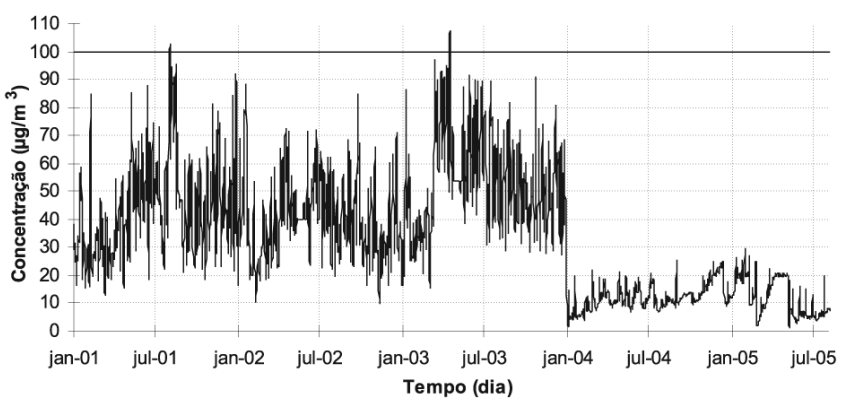

Figura 3. Médias diárias das concentrações horárias de $\mathrm{SO}_{2}$ em Laranjeiras. A linha representa o padrão secundário ${ }^{15}$ para $\mathrm{SO}_{2}\left(100 \mu \mathrm{g} \mathrm{m} \mathrm{m}^{-3}\right)$

Para o $\mathrm{NO}_{2}$ (dados disponíveis apenas a partir de 2003), as menores concentrações horárias foram observadas em LAR (Figura 4), onde na maioria das vezes se encontra abaixo de $40 \mu \mathrm{g} \mathrm{m}^{-3}$. Nas outras estações houve maior número de registro de concentrações acima de $60 \mu \mathrm{g} \mathrm{m}^{-3}$, principalmente na ENS (Figura 5S) onde foi registrada a ocorrência de picos acima de $160 \mu \mathrm{g} \mathrm{m}^{-3}$. As concentrações horárias de $\mathrm{NO}_{2}$ no IBV são apresentadas na Figura 6S. As concentrações de

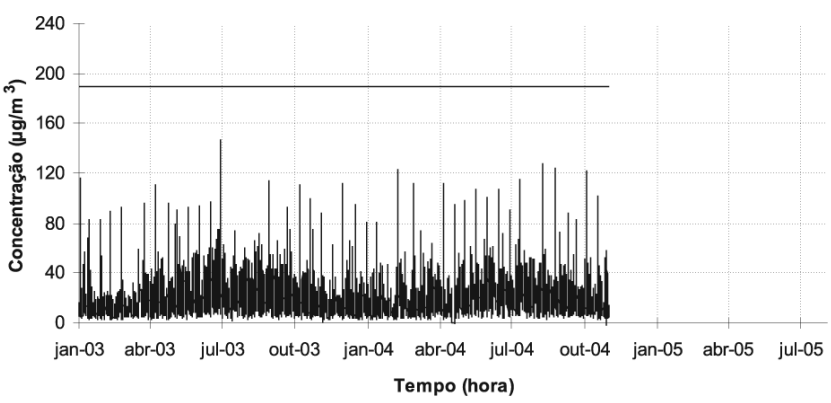

Figura 4. Médias horárias das concentrações $\mathrm{NO}_{2}$ em Laranjeiras (com dados invalidados a partir de 11/2004). A linha representa o padrão secundário ${ }^{15}$ para $\mathrm{NO}_{2} \cdot\left(190 \mu \mathrm{g} \mathrm{m}^{-3}\right)$ 
$\mathrm{NO}_{2}$ no inverno são maiores em todas as estações, comportamento similar a vários poluentes. De acordo com os dados, os valores dos padrões primário $\left(320 \mu \mathrm{g} \mathrm{m}^{-3}\right)$ e secundário $\left(190 \mu \mathrm{g} \mathrm{m}^{-3}\right)$ para as médias horárias de $\mathrm{NO}_{2}$ nunca foram ultrapassadas.

\section{Análise das concentrações de ozônio}

Os dados acumulativos de ozônio são apresentados na Tabela 2 para as três estações em estudo, para quatro períodos (1, 3, 6 e 12 meses) anteriores a cada campanha. A estação do IBV, no período de 6 meses anteriores à $1^{\mathrm{a}}$ campanha $(\mathrm{C} 1)$, apresentou valores maiores que $10000 \mathrm{ppb} \mathrm{h}^{-1}$ para o AOT-40 durante 6 meses. Estes valores violam as diretrizes propostas por OMS, ${ }^{31}$ para os níveis críticos de ozônio para vegetais terrestres. Para a $3^{\mathrm{a}}$ campanha (C3), o AOT-40 no IBV para 1 ano foi de cerca de $20000 \mathrm{ppb} \mathrm{h}^{-1}$. O AOT-40, medido em 6 meses, apresentou diminuição no IBV, enquanto o AOT-40 medido em 1 ano aumentou em LAR ao longo das campanhas. A ENS apresentou poucos valores acima de $60 \mathrm{ppb} \mathrm{h}^{-1}$ (SUM-60) enquanto que, no geral, a estação do IBV apresentou os maiores valores nesta metodologia. Nos períodos de 1 ano anteriores à $\mathrm{C} 1$, os valores de SUM 60 no IBV estiveram acima de 1000 ppb. LAR apresentou $467 \mathrm{ppb} \mathrm{h}^{-1}$ para SUM 60 em 1 mês de exposição anterior à $2^{\mathrm{a}}$ campanha $(\mathrm{C} 2)$, indicando registro de altas concentrações de ozônio para este período. Os valores de SUM 0 aumentaram no decorrer da realização das campanhas. O IBV apresenta os maiores valores para SUM 0 e AOT-40, enquanto que LAR apresentou os maiores valores para SUM-60 em todas as campanhas, exceto C1. De acordo com estas medidas acumulativas, a ENS é o local com menores concentrações de ozônio. Para C3, não foi possível calcular os valores acumulativos de ozônio devido à interrupção da aquisição desses dados. Por ser considerada uma região livre de altas concentrações de ozônio, é bastante provável que os valores de AOT-40 e SUM-60 para RDB sejam iguais a zero. Entretanto, para SUM-0, deve-se levar em conta as concentrações de back-ground na região, que no campo estão abaixo de 40 ppb. ${ }^{32}$

As médias móveis com tempo de exposição de 4 h em LAR (Figura 5) atingiram valores de até $140 \mu \mathrm{g} \mathrm{m}^{-3} \mathrm{em} \mathrm{mar/2004} \mathrm{e} \mathrm{out/2004.} \mathrm{Os}$ valores mais altos comumente observados ficaram em torno de $80 \mu \mathrm{g}$ $\mathrm{m}^{-3}$. Os menores valores foram observados em Fev/2002, mostrando concentrações $40 \mu \mathrm{g} \mathrm{m}^{-3}$. Para ago/2005 foram observados valores de 80 a $90 \mu \mathrm{g} \mathrm{m}^{-3}$. Em out/2004 e nov/2004, os valores das médias móveis para $4 \mathrm{~h}$ de exposição em LAR apresentaram-se constantemente acima do limiar de injúria foliar em tabaco, legumes e orquídeas proposto

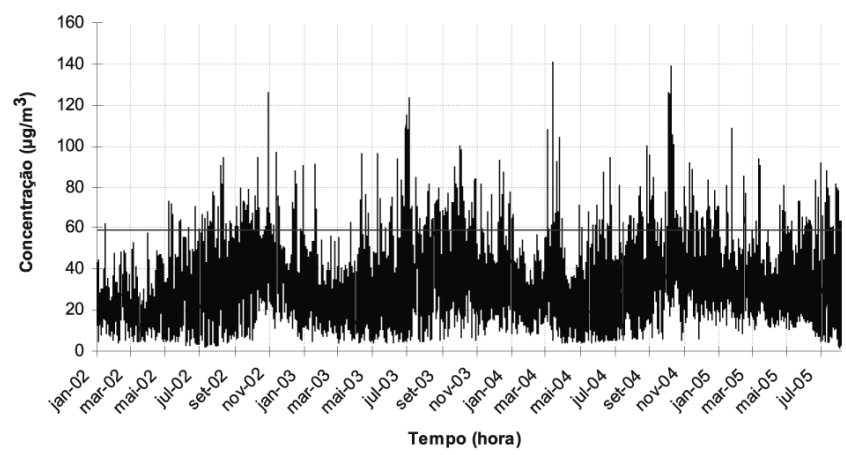

Figura 5. Médias móveis das concentrações de ozônio para 4 h de exposição em Laranjeiras. Indicação de Stern ${ }^{l}$ em destaque $\left(59 \mu \mathrm{g} \mathrm{m}^{-3}\right)$

por Stern. ${ }^{1} \mathrm{Na}$ ENS, as médias móveis com tempo de exposição de 4 $\mathrm{h}$ (Figura $7 \mathrm{~S}$ ) atingiram valores superiores a $100 \mu \mathrm{g} \mathrm{m} \mathrm{m}^{-3} \mathrm{em} \mathrm{ago/2003.}$ Os valores mais altos comumente observados ficaram em torno de $80 \mu \mathrm{g} \mathrm{m}^{-3}$. Em mar/2002 foram observados os menores valores, mostrando concentrações de $30 \mu \mathrm{g} \mathrm{m}^{-3}$. As médias móveis com tempo de exposição de $4 \mathrm{~h}$ no IBV (Figura $8 \mathrm{~S}$ ) atingiram valores superiores a $120 \mu \mathrm{g} \mathrm{m}^{-3} \mathrm{em} \mathrm{mai} / 2002$, nov/2002, out/2003, set/2004 e jan/2005. Os valores mais altos comumente observados ficaram em torno de $80 \mu \mathrm{g} \mathrm{m}^{-3}$, porém muitos valores de $100 \mu \mathrm{g} \mathrm{m}^{-3}$ foram observados. Para ago/2005 foram observadas concentrações de 40 a $80 \mu \mathrm{g} \mathrm{m}^{-3}$. As análises das concentrações de ozônio em períodos anteriores à C3 foram comprometidas, devido à interrupção da aquisição dos dados horários de ozônio a partir do dia 29 de junho de 2005 na ENS.

As médias móveis com tempo de exposição de 4 h mostraram maiores concentrações de ozônio no mês de outubro, que se deve ao aumento da incidência da radiação solar a partir deste mês, o que contribui para o aumento na concentração de ozônio. A radiação solar incidente contribui para os mecanismos de formação do ozônio na troposfera. Entretanto, esta tendência de aumento da concentração de ozônio não é observada a partir de janeiro, provavelmente devido ao aumento da turbulência atmosférica e do aumento da pluviosidade, que dificulta a incidência de radiação solar.

\section{Parâmetros bioquímicos}

$\mathrm{Na} 1^{\mathrm{a}}$ campanha $(\mathrm{C} 1)$, foram consideradas folhas coletadas nos dias 3 de outubro de 2003 e 4 de novembro de 2003. Esta unificação só foi possível porque não houve variação considerável dos parâme-

Tabela 2. Análise acumulativa das concentrações de ozônio nas estações

\begin{tabular}{lcccccccccc}
\hline \multirow{2}{*}{ Campanha } & $\begin{array}{c}\text { Período } \\
\text { anterior }\end{array}$ & SUM 0 & AOT 40 & SUM 60 & SUM 0 & AOT 40 & SUM 60 & SUM 0 & AOT 40 & SUM 60 \\
\hline & 1 mês & 15446 & 744 & 0 & 14664 & 429 & 0 & 16340 & 1272 & 121 \\
C1 & 3 meses & 45044 & 1181 & 0 & 46440 & 2617 & 63 & 50711 & 5391 & 433 \\
(Nov/ & 6 meses & 67923 & 2884 & 121 & 84199 & 5988 & 436 & 93517 & 12864 & 1026 \\
Out/2003) & 1 ano & 124085 & 3827 & 121 & 146787 & 7681 & 436 & 160638 & 16842 & 1347 \\
\hline & 1 mês & 11602 & 44 & 0 & 13761 & 0 & 467 & 15587 & 1388 & 0 \\
C2 & 3 meses & 35263 & 691 & 0 & 48259 & 6109 & 992 & 51695 & 5541 & 124 \\
(Dez/2004) & 6 meses & 71133 & 1445 & 0 & 86450 & 7862 & 992 & 94940 & 10407 & 563 \\
& 1 ano & 129355 & 1895 & 0 & 147066 & 10054 & 1467 & 157211 & 11606 & 624 \\
\hline & 1 mês & $*$ & $*$ & $*$ & 13369 & 1270 & 0 & 18325 & 3774 & 0 \\
C3 & 3 meses & $*$ & $*$ & $*$ & 35231 & 1970 & 0 & 45238 & 5893 & 0 \\
(Ago/2005) & 6 meses & $*$ & $*$ & $*$ & 68899 & 2950 & 0 & 83938 & 8291 & 0 \\
& 1 ano & $*$ & $*$ & $*$ & 158703 & 11528 & 992 & 183464 & 19461 & 623 \\
\hline
\end{tabular}

*Dados invalidados a partir de 14 h e 30 min do dia 29 de junho de 2005 . Unidade $=\mathrm{ppb} \mathrm{h}^{-1}$. 
tros bioquímicos avaliados para os mesmos locais entre os dias de coleta. Nesta campanha não foram realizadas as análises de clorofilas e $\beta$-caroteno. A $2^{\mathrm{a}}$ campanha $(\mathrm{C} 2)$ e a $3^{\mathrm{a}}$ campanha $(\mathrm{C} 3)$ foram realizadas nos dias 18 de dezembro de 2004 e 4 de agosto de 2005, respectivamente. Nestas campanhas, todos os parâmetros descritos neste trabalho foram medidos. A Tabela $1 \mathrm{~S}$ apresenta os resultados das análises dos parâmetros bioquímicos da Licania tomentosa e a Tabela 2S mostra os resultados da Bauhinia forficata.

\section{Influência da concentração de ozônio nas alterações bioquímicas}

A avaliação da qualidade do ar da RGV mostrou que o ozônio apresentou concentrações mais críticas para as espécies vegetais, visto que, na maior parte do tempo, ultrapassaram os limites propostos por Stern. ${ }^{1} \mathrm{PM}_{10}, \mathrm{SO}_{2}$ e $\mathrm{NO}_{2}$ não apresentaram concentrações acima dos limites propostos, tampouco apresentaram concentrações acima dos seus padrões primário e secundário. Dessa forma, optou-se pela tentativa de explicar as alterações bioquímicas através das concentrações do ozônio, considerando que este poluente representaria bem a capacidade oxidante do ar da região em estudo. Além disso, foi levada em conta a capacidade de alteração específica do ozônio sobre espécies vegetais. Essa capacidade de alteração específica é resultado direto da seletividade deste poluente que pode ser, por exemplo, a acumulação de proteínas produzidas, a produção de enzimas anti-oxidantes ou, então, o consumo de ácido ascórbico. ${ }^{10}$

LAR apresentou os maiores valores de $\mathrm{pH}$ na $\mathrm{C} 2$, porém não foi significativamente diferente em relação à RDB para as espécies. As concentrações de ozônio em LAR apresentaram picos entre 120 e 140 $\mu \mathrm{g} \mathrm{m}^{-3}$ para as médias móveis. Os valores de SUM 60 em LAR para 1 mês de exposição foram de $467 \mathrm{ppb} \mathrm{h}^{-1}$, mostrando que as espécies apresentaram elevados picos de concentrações de ozônio, podendo ser o principal motivo das alterações ocorridas para as espécies. Entretanto, apesar das maiores concentrações de ozônio em LAR para $\mathrm{C} 2$, existe a possibilidade da espécie pata-de-vaca ter sofrido interferência do solo de LAR, especialmente devido à escassez de magnésio e de matéria orgânica. LAR apresentou os maiores valores de $\mathrm{BCI}$ na pata-de-vaca para a $\mathrm{C} 2$. O pH e o BCI do meio celular das espécies estudadas tendem a ser maiores em locais potencialmente poluídos, demonstrando a existência de um possível mecanismo de defesa destas plantas contra os poluentes atmosféricos, que podem ser neutralizados pela maior alcalinidade das folhas. A pata-de-vaca do IBV pode ter comprometido sua capacidade de tamponamento, devido à maior exposição aos poluentes.

As espécies de oiti do IBV apresentaram maiores concentrações de ácido ascórbico em suas folhagens em comparação aos outros locais na C1. O SUM 0, SUM 60 e AOT-40 foram maiores no IBV durante todos os períodos de tempo analisados (1, 3, 6 e 12 meses). As médias móveis para $4 \mathrm{~h}$ de exposição apresentam picos superiores a $100 \mu \mathrm{g} \mathrm{m}^{-3}$ nos períodos de $\mathrm{C} 1$, chegando a medir até $120 \mu \mathrm{g} \mathrm{m}^{-3}$. A elevada carga de ozônio no IBV pode ter provocado a produção de ácido ascórbico pela pata-de-vaca, funcionando com um mecanismo de defesa contra a ação oxidante deste poluente. $\mathrm{O}$ ácido ascórbico apresenta maiores concentrações no oiti do IBV, enquanto a pata-devaca tende a apresentar mais ácido ascórbico nas folhagens de RDB. O oiti parece utilizar o ácido ascórbico como mecanismo de defesa contra a ação de poluentes oxidantes como ozônio, pois produz mais ácido ascórbico em condições de estresse por poluição atmosférica. Na pata-de-vaca, o teor de ácido ascórbico tende a apresentar menores concentrações nas folhagens de locais mais poluídos por ozônio. Para a pata-de-vaca, pode haver um consumo de ácido ascórbico na planta por parte do ozônio e de outros poluentes presentes. Entretanto, é importante salientar que o ácido ascórbico da pata-de-vaca sofreu considerável diminuição no inverno. Essa diminuição se reduziu a um terço da concentração no verão. Da mesma forma, as clorofilas também sofreram diminuição de um quinto de sua concentração no inverno.

A atividade de peroxidase apresenta grandes variações entre indivíduos de mesmos locais, implicando em grandes faixas de incertezas em torno das médias, dificultando o fornecimento de respostas acerca das alterações deste parâmetro. Ainda assim, foi possível observar tendência de diminuição da atividade de peroxidase do oiti com o aumento da concentração de ozônio medido em SUM-0. A invalidação dos dados de ozônio impossibilitou respostas para a alteração da atividade de peroxidase na pata-de-vaca da ENS na C3.

Clorofilas totais mostraram alterações significantes que podem ser comparadas às altas concentrações acumulativas de ozônio na RGV. Menores concentrações de clorofilas totais do oiti foram observadas no IBV, estação esta que apresenta os maiores valores de AOT-40. O teor de $\beta$-caroteno e a clorofila $B$ da pata-de-vaca podem ser influenciados pela concentração do ozônio no ar, diminuindo na presença de altas concentrações de ozônio, como em LAR para C2. Clorofila $\mathrm{B}$ e $\beta$-caroteno atuam como pigmentos fotoprotetores, portanto, uma alteração no seu conteúdo constitui uma resposta das plantas aos fatores de estresse por poluentes atmosféricos. Os carotenóides e clorofilas são substâncias anti-oxidantes, que são consumidas na presença de poluente oxidante, como o ozônio. Nota-se uma menor relação de clorofila $\mathrm{A} / \mathrm{B}$ no oiti em LAR e maior no IBV para $\mathrm{C} 2$. A relação clorofila $\mathrm{A} / \mathrm{B}$ constitui um bom parâmetro bioindicador de alterações ambientais. ${ }^{33}$ Possivelmente, a relação clorofila A/B sofre maior variação nos locais poluídos, devido a maior necessidade de produção de clorofila B para manter compostos antioxidantes no meio foliar.

A grande frequiência de altas médias de ozônio no IBV (valores acima de $59 \mu \mathrm{g} \mathrm{m}^{-3}$ ) pode justificar algumas alterações bioquímicas ocorridas nas espécies deste local, especialmente para o oiti. O ácido ascórbico do oiti do IBV apresentou maiores concentrações na C1. Altas concentrações de ozônio podem provocar produção de ácido ascórbico pelas plantas, as quais o utilizam como anti-oxidante contra a ação do ozônio. Os teores de clorofila B e de clorofila total no oiti do IBV foram os menores para a C2. Na C2, a estação do IBV apresentou elevados picos para média móvel para 4 h de exposição, alcançando valores acima de $120 \mu \mathrm{g} \mathrm{m}^{-3}$. Concentrações muito elevadas de ozônio podem consumir a clorofila B das plantas, que ao invés de utilizá-la para a absorção da radiação solar para fotossíntese, também a utiliza como antioxidante de poluentes atmosféricos.

A Tabela 3S mostra a relação entre as concentrações de poluentes e as alterações bioquímicas nas folhas das espécies vegetais. As médias móveis na estação do IBV foram altas em períodos anteriores à $\mathrm{C} 1$ e $\mathrm{C} 2$, e as maiores excedências também foram verificadas neste local, para todas as campanhas.

A atividade de peroxidase da pata-de-vaca foi muito maior em LAR frente aos outros locais na $\mathrm{C} 2$. Um aumento em torno de 3 vezes na atividade desta enzima neste local pode ser consequiência dos grandes picos nas médias observadas em LAR para esta campanha. $\mathrm{O}$ estresse devido à alta carga de ozônio pode ter propiciado formação de peróxidos na pata-de-vaca, acarretando demasiada formação da enzima peroxidase. A clorofila B também foi outro parâmetro que se alterou em LAR na C2, tanto para a pata-de-vaca, quanto para o oiti. A pata-de-vaca registrou os menores valores de clorofila $B$, enquanto o oiti os maiores. A relação clorofila $\mathrm{A} / \mathrm{B}$ mostrou-se menor para o oiti em LAR em comparação aos outros locais, enquanto que na pata-de-vaca não foi estatisticamente diferente.

As concentrações de $\mathrm{SO}_{2}$ são ligeiramente maiores na ENS, apresentando valores entre 25 e $30 \mu \mathrm{g} \mathrm{m}^{-3}$. ENS não apresentou alterações bioquímicas nas espécies, exceto a elevada atividade de peroxidase 
da pata-de-vaca em C3. Entretanto, em C3, as concentrações de $\mathrm{SO}_{2}$ ficaram entre $25 \mu \mathrm{g} \mathrm{m}^{-3}$. As concentrações de $\mathrm{NO}_{2}$ ficaram entre 40 e $50 \mu \mathrm{g} \mathrm{m}^{-3} \mathrm{em}$ todas as estações e $\mathrm{PM}_{10}$ entre 40 e $60 \mu \mathrm{g} \mathrm{m}^{-3}$, sendo ligeiramente maior em LAR nas $\mathrm{C} 1$ e $\mathrm{C} 2$, onde apresentou concentrações de $60 \mu \mathrm{g} \mathrm{m}^{-3}$.

As altas concentrações das médias móveis verificadas em LAR na $\mathrm{C} 2$ (valores entre 120 e $140 \mu \mathrm{g} \mathrm{m}^{-3}$ ) podem justificar o grande número de alterações bioquímicas ocorridas nas espécies deste local, especialmente para a pata-de-vaca. $\mathrm{O}$ pH da pata-de-vaca teve um aumento considerável, destacando-se dos outros locais. Ao mesmo tempo, o BCI também se elevou. A hipótese da formação de um mecanismo de defesa contra a ação de poluentes ácidos e de ozônio é reforçada por estas alterações.

A ENS é o local que registra as menores médias móveis para tempo de exposição de $4 \mathrm{~h}$. Esta estação também foi a que apresentou menos alterações bioquímicas nas espécies, entretanto, a atividade de peroxidase da pata-de-vaca na C3 foi maior frente aos outros locais. Como as concentrações de $\mathrm{PM}_{10}, \mathrm{SO}_{2}$ e $\mathrm{NO}_{2}$ não apresentaram comportamento anormal neste período, a falta de dados de ozônio para esta estação neste período comprometeu a discussão do fenômeno ocorrido neste local.

IBV e LAR foram as estações analisadas que registraram as maiores concentrações de ozônio da Região da Grande Vitória. As concentrações horárias de ozônio nas estações estudadas raramente ultrapassam o padrão secundário. ${ }^{15}$ Entretanto, as médias móveis para $4 \mathrm{~h}$ de exposição geralmente ultrapassam o limite proposto para o limiar de efeitos em legumes, orquídeas e tabaco. O AOT-40 apresenta valores elevados, principalmente no IBV, onde os valores, na $\mathrm{C} 1$ e C2, ultrapassaram 10000 ppb para 6 meses, que é o valor proposto pela OMS $^{31}$ como padrão de concentração para ozônio. As concentrações de ozônio são maiores nos períodos de transição do inverno para o verão nas estações da RGV, pois ocorre um aumento da radiação solar com índices pluviométricos menores que no verão.

As alterações bioquímicas podem ter relação direta com a ação de poluentes atmosféricos como o ozônio, na suscetibilidade da planta a patógenos e ao ataque de herbívoros. Ao causar modificação da superfície foliar, um poluente pode facilitar a perda de água e cátions. Isso acarreta numa facilitação da penetração e infecção da folha por patógenos e outros parasitas. ${ }^{34}$

A bioindicação consiste no estudo da resposta de um organismo à poluição ambiental. O biomonitoramento utiliza continuamente estas respostas dadas pelos bioindicadores para avaliar a qualidade do ar de uma região. Existem dois tipos clássicos de biomonitoramento: o passivo e o ativo. No passivo, o bioindicador se encontra nas condições naturais do ambiente, e originalmente pertence ao meio. ${ }^{5}$ No ativo, o bioindicador é implantado no meio em estudo e exposto a situações controladas, tais como solo e disponibilidade de água e luz. ${ }^{35}$

O biomonitoramento atmosférico, com o uso de vegetais como ferramenta na avaliação da qualidade do ar, pode reproduzir a qualidade do ar de uma localidade, uma vez que avalia respostas de sistemas biológicos de modo integrado. ${ }^{9}$ Os parâmetros bioquímicos avaliados neste trabalho apresentam metodologias simples, rápida e de baixo custo, que podem ser realizadas no próprio campo.

Dessa forma, as espécies Licania tomentosa e Bauhinia forficata são indicadas para o biomonitoramento passivo, enquanto que outras espécies referenciadas na literatura como bioindicadores de ozônio, tais como a tradescantia ${ }^{7}$ e o tabaco ${ }^{8}$ são empregadas no biomonitoramento ativo.

\section{CONCLUSÃO}

As análises feitas neste trabalho mostraram que parâmetros bioquímicos, como $\mathrm{pH}, \mathrm{BCI}$, ácido ascórbico, atividade de peroxidase e clorofilas totais na espécie Licania tomentosa (oiti) e pH, BCI, clorofila B e $\beta$-caroteno na espécie Bauhinia forficata (pata-de-vaca) avaliadas nas estações da Enseada do Suá (ENS), Laranjeiras (LAR), Ibes (IBV) e na Reserva Ecológica de Duas Bocas (RDB), durante as campanhas de out/nov/2003 (C1), dez/2004 (C2) e ago/2005 (C3), sofreram alterações entre os locais, constituindo-se em potenciais indicadores de estresse causado pela poluição do ar, especialmente por ozônio.

A média móvel para $4 \mathrm{~h}$ de exposição e o AOT-40 parecem ser as metodologias de cálculo da concentração de ozônio mais adequadas para este estudo, pois se relacionaram com a maior parte das alterações bioquímicas das folhas.

A concentração de magnésio e de matéria orgânica no solo de LAR foi muito pequena. Como LAR foi o local que apresentou o maior número de alterações bioquímicas, existe a possibilidade de algumas alterações nos parâmetros bioquímicos serem proporcionadas pela qualidade do solo. Ainda assim, o efeito sinérgico dos fatores solo e ar pode ser ainda mais agressivo nas alterações bioquímicas nas espécies estudadas. Variações sazonais no clima devido às estações do ano também influenciaram algumas alterações bioquímicas, especialmente na pata-de-vaca, a qual é considerada uma espécie perenifólia.

Apesar dos resultados contribuírem para melhor entendimento da influência das variações ambientais sobre as espécies vegetais nativas da Região da Grande Vitória, são necessários estudos sob condições controladas que acondicionem os efeitos específicos do ozônio sobre as espécies estudadas, ou seja, realização de experimentos com as espécies em laboratório.

As alterações bioquímicas identificadas nas espécies localizadas nas estações da Enseada do Suá, Laranjeiras e Ibes servem de alerta para o controle da concentração de poluentes atmosféricos. Este controle visaria principalmente a proteção das espécies vegetais nativas da Região da Grande Vitória e passaria pela adoção de padrões secundários de concentrações de poluentes mais adequados, especialmente para o ozônio. Além disso, estas medidas podem ser confirmadas através do estabelecimento de um programa de biomonitoramento para a Região da Grande Vitória, onde as espécies Licania tomentosa e Bauhinia forficata poderiam ser usadas em conjunto com outras espécies para um biomonitoramento passivo e ativo.

\section{MATERIAL SUPLEMENTAR}

No material suplementar, disponível gratuitamente em http:// quimicanova.sbq.org.br, na forma de arquivo PDF, encontram-se as Figuras $1 \mathrm{~S}$ a $8 \mathrm{~S}$ e as Tabelas $1 \mathrm{~S}$ a $3 \mathrm{~S}$.

\section{AGRADECIMENTOS}

Ao LABSAN-UFES pelos auxílios recebidos na realização das análises bioquímicas. Ao IEMA pelo fornecimento das concentrações horárias dos poluentes atmosféricos. Ao CNPQ pela concessão de bolsa de mestrado a O. L. G. Maioli e demais suportes financeiros.

\section{REFERÊNCIAS}

1. Stern, A. C.; Boubel, R. W.; Turner, D. B.; Fox, D. L.; Fundamentals of air pollution, $2^{\text {nd }}$ ed., Academic Press: New York, 1984.

2. Bussoti, F.; Ferreti, M.; Environ. Pollut. 1998, 101, 49.

3. Agrios, G. M.; Plant Pathology, $3^{\text {rd }}$ ed., Academic Press: London, 1988.

4. Manning, W. J.; Godzik, B.; Environ. Pollut. 2003, 130, 33.

5. El-Khatib, A. A.; Environ. Pollut. 2003, 124, 419.

6. Biolley J.; Goulas, P.; Leitão, L; Plant Sci. 2003, 163, 613. 
7. Guimarães, E. T.; Domingos, M.; Alves, E. S.; Caldini, N.; Lobo, D. J. A.; Lichtenfels, A. J. F. C., Saldiva, P. H. N.; Environmental and Experimental Botany 2000, 44, 1.

8. Saitanis, C. J.; Riga-Karandinos, A. N.; Karandinos, C. J.; Chemosphere 2001, 42, 945 .

9. http://www.ietec.com.br/techoje/meioambiente/ab0007-2.htm, acessada em Abril 2005

10. Sharma, Y. K.; Davis, K. R.; Free Radical Biol. Med. 1997, 23, 480.

11. Klumpp, G.; Furlan, C. M.; Domingos, M.; Klumpp, A.; Sci. Total Environ. 2000, 246, 79 .

12. Wittig, R.; Em Plants as Biomonitors. Indicators for Heavy Metals in the Terrestrial Environment; Markert, B., ed.; VCH: Wheinheim, 1993, p. 3.

13. Silveira, A. B.; Santos, J. M.; Reis Jr., N. C.; Pereira, M. M. R.; Resumos do $23^{\circ}$ Congresso Brasileiro de Engenharia Sanitária e Ambiental, Campo Grande, Brasil, 2005.

14. Serviço Nacional de Levantamento e Conservação de Solos; Manual de métodos de análise de solos. $2^{\mathrm{a}}$ ed., Rio de Janeiro, 1997, p. 212.

15. Resolução Conama ${ }^{\circ}$ 003, de 28 de junho de 1990. Padrões de qualidade do ar para os poluentes regulamentados; Diário Oficial da União, Seção I, Brasília, 22/8/1990. 15.937.

16. http://www.fiaozone.net/exposuredescrip.htm, acessada em Maio 2004

17. Fumagalli, I.; Mignanego, L.; Mills, G.; Agriculture, Ecosystems and Environment 2003, 95, 119.

18. Fontes, P. C. R.; Diagnóstico do estado nutricional das plantas, $20^{a}$ ed., Universidade Federal de Viçosa: Viçosa, 2001.

19. Pylypec, B.; Redmann, R.; Canadian Journal of Botany 1984, 62, 2650.
20. Bender, J.; Jager, H. J.; Seufert, G.; Arndt, U.; Augew Bot. 1986, 60, 461.

21. Freebairn, H. T.; Anal. Chem.. 1959, 31, 1850.

22. Lewin, S.; Vitamin C: Its Molecular Biology and Medical Potential, Academic Press: London, New York, San Francisco, 1976.

23. Kim, Y. H.; Yoo, J. Y.; Enzyme Microb. Technol. 1996, 18, 531.

24. Jeffrey, S. W.; Humphrey, G. F.; Biochemistry and Physiology Pflanzen 1975, 167, 191.

25. Kirk, J. T. O.; Allen, R. L.; Biochem. Biophys. Res. Commun. 1965, 21, 523.

26. Raven, P. H.; Evert, R. F.; Eichhorn, S. E.; Biologia Vegetal, $6^{a}$ ed., Editora Guanabara: Rio de Janeiro, 2001.

27. Sales, H. B.; Divulgação Técnica Ano XXIII 2005, 168.

28. Yamada, T.; Informações Agronômicas 2004, 108, 1.

29. Huber, D. M.; Em Plant Pathology; An Advenced Treatise; Horsfall, L.; Cowling, E. B., eds.; Academic Press: New York 1980, vol. 5, p. 381.

30. Piccolo, A.; Nardi, S.; Concheri, G.; Soil Biol. Biochem. 1992, 24, 373.

31. Regional Office for Europ; Air Quality Guidelines, $2^{\text {nd }}$ ed., Copenhagen, Denmark, 2000.

32. Seinfeld, J. H.; Pandis, S. N.; Atmospheric Chemistry and Physics - From Air Pollution to Climate Change, Wiley Interscience: New York, 1998.

33. Gonçalves, J. F.; Marenco, R. A.; Vieira, G.; Revista Brasileira de Fisiologia Vegetal 2001, 13, 149.

34. Poborski, P. S.; Elsevier Applied Science, Elsevier: London, New York, 1987, p. 91.

35. Pandey, J.; Agrawal, M.; The New Phytologist 1994, 126, 53. 
PARÂMETROS BIOQUÍMICOS FOLIARES DAS ESPÉCIES Licania tomentosa (BENTH.) E Bauhinia forficata (LINK.) PARA AVALIAÇÃO DA QUALIDADE DO AR

Otávio Luiz Gusso Maioli*, Jane Meri Santos, Neyval Costa Reis Júnior e Sérvio Túlio Alves Cassini

Departamento de Engenharia Ambiental, Universidade Federal do Espírito Santo, 29075-910 Vitória - ES, Brasil

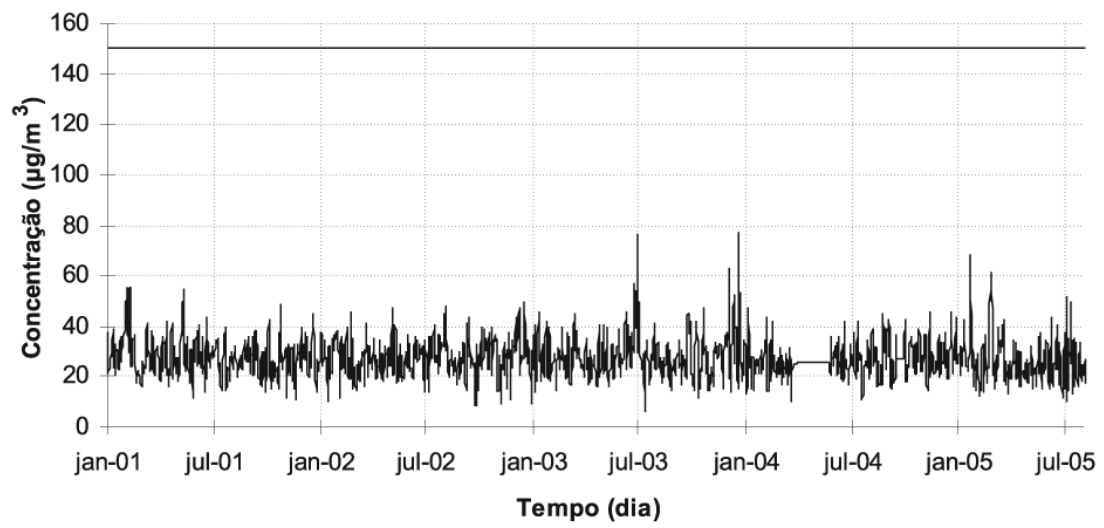

Figura 1S. Médias diárias das concentrações horárias de $P M_{10}$ na Enseada do Suá. A linha representa o padrão secundário ${ }^{15}$ para $P M_{10}\left(150 \mu g m^{-3}\right)$

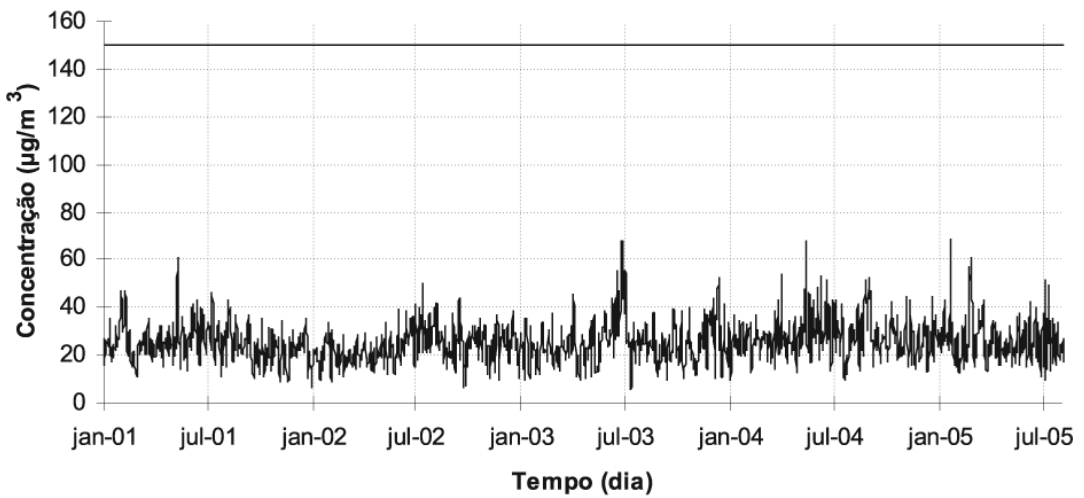

Figura 2S. Médias diárias das concentrações horárias de $P M_{10}$ no Ibes. A linha representa o padrão secundário ${ }^{15}$ para $P M_{10}\left(150 \mu \mathrm{g} \mathrm{m}^{-3}\right)$

*e-mail: otaviomaioli@iq.ufrj.br 


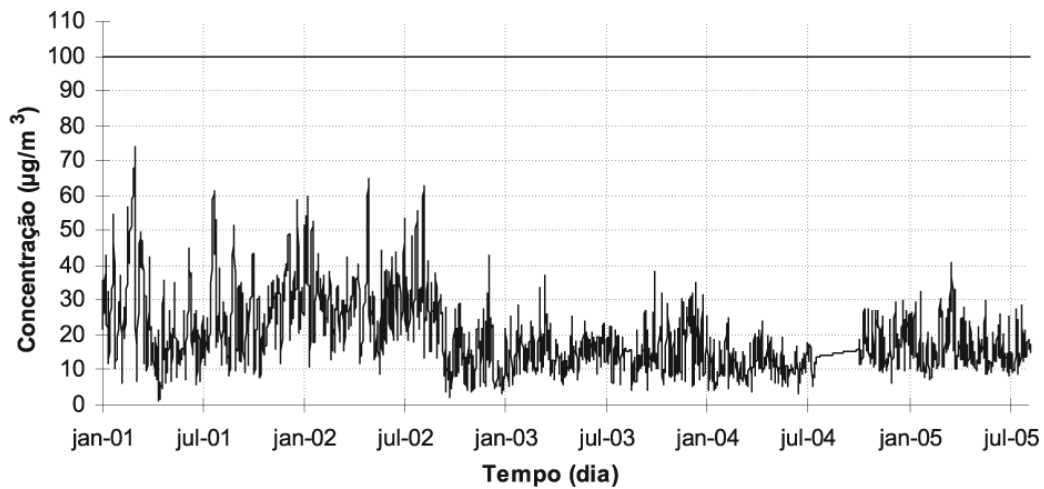

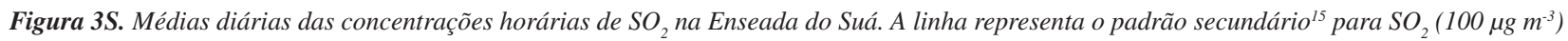

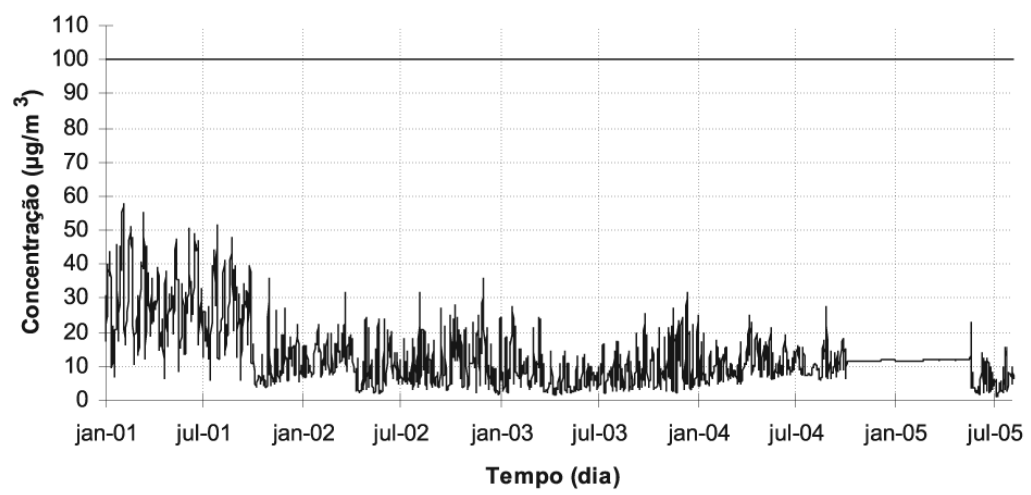

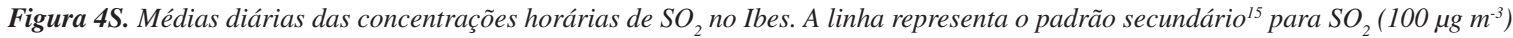

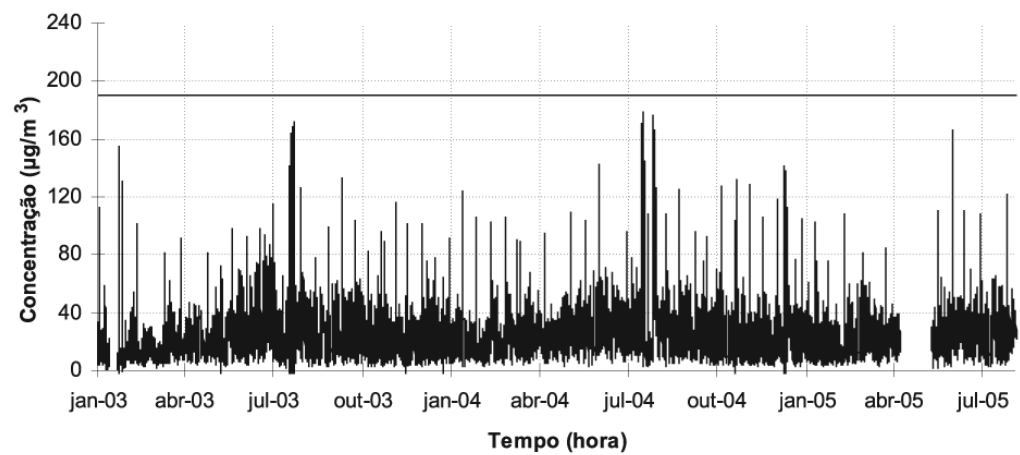

Figura 5S. Médias horárias das concentrações $\mathrm{NO}_{2}$ na Enseada do Suá. A linha representa o padrão secundário ${ }^{15}$ para $\mathrm{NO}_{2}\left(190 \mu \mathrm{g} \mathrm{m}^{-3}\right)$ 


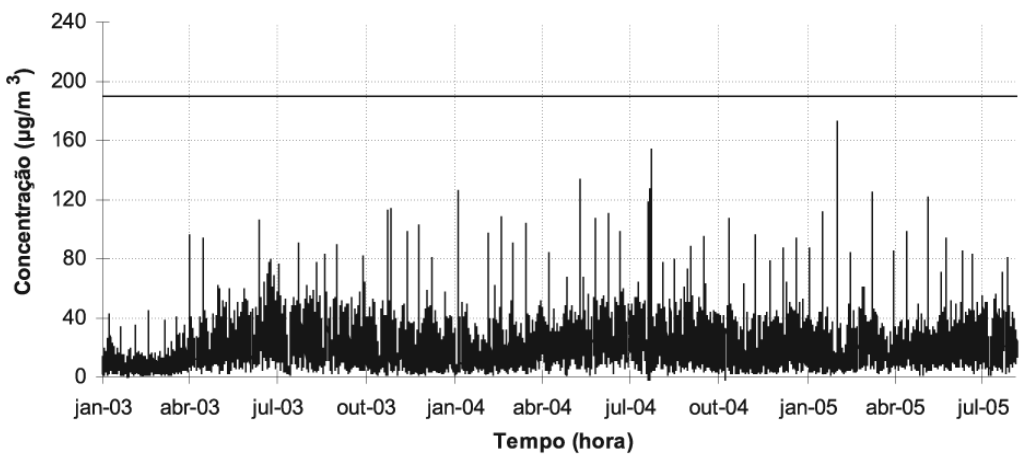

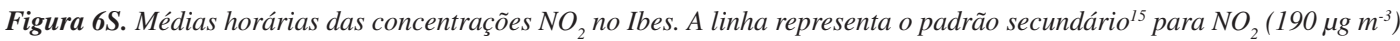

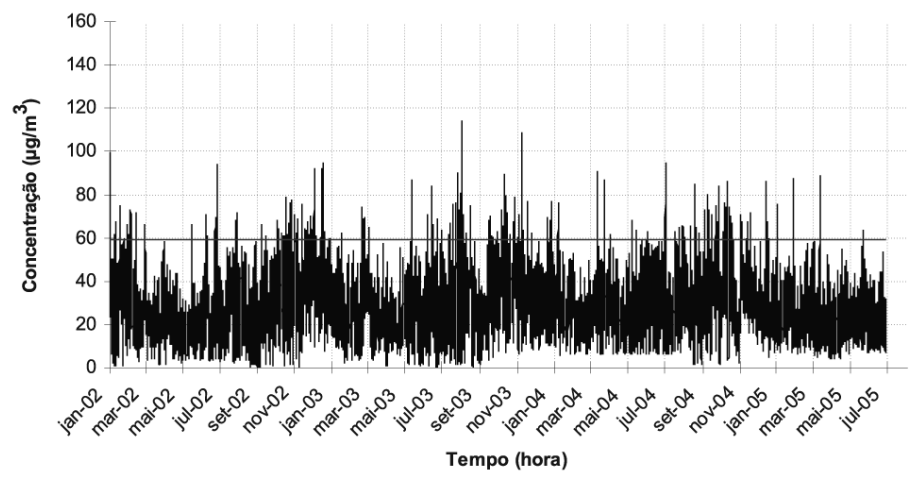

Figura 7S. Médias móveis das concentrações de ozônio para 4 h de exposição na Enseada do Suá. Indicação de Stern em destaque (59 $\left.\mu g m^{-3}\right)$

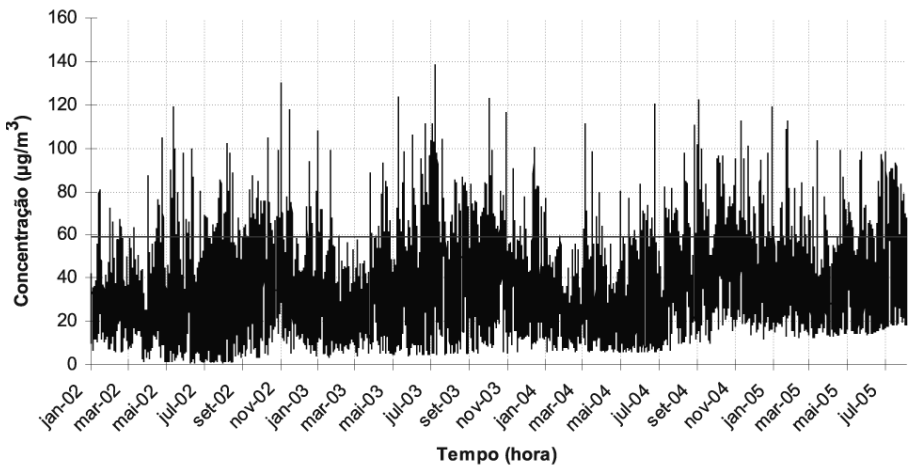

Figura 8S. Médias móveis das concentrações de ozônio para 4 h de exposição no Ibes. Indicação de Stern em destaque $\left(59 \mu \mathrm{g} \mathrm{m}^{-3}\right)$ 
Tabela 1S. Parâmetros bioquímicos da espécie Licania tomentosa nos locais estudados para cada campanha de coleta de folhas

\begin{tabular}{|c|c|c|c|c|c|c|c|c|c|c|}
\hline $\begin{array}{l}\text { Campanha } \\
\text { de coleta } \\
\text { de folhas }\end{array}$ & Local & $\mathrm{pH}$ & BCI. $\left(10^{-2}\right)$ & $\begin{array}{c}\text { Ácido } \\
\text { Ascórbico } \\
\left(\mathrm{mg} \mathrm{g}^{-1}\right. \\
\text { de folha) }\end{array}$ & $\begin{array}{c}\text { Peroxidase } \\
\quad\left(\mathrm{U} \mathrm{g}^{-1}\right. \\
\text { de folha) }\end{array}$ & $\begin{array}{c}\beta \text {-caroteno } \\
\left(\mu \mathrm{g} \mathrm{g}^{-1}\right. \\
\text { de folha })\end{array}$ & $\begin{array}{l}\text { Clorofila A } \\
\qquad\left(\mu \mathrm{g} \mathrm{g}^{-1}\right. \\
\text { de folha })\end{array}$ & $\begin{array}{l}\text { Clorofila B } \\
\qquad\left(\mu \mathrm{g} \mathrm{g}^{-1}\right. \\
\text { de folha) }\end{array}$ & $\begin{array}{c}\text { Clorofila } \\
\text { A/B }\end{array}$ & $\begin{array}{l}\text { Clorofila Total } \\
\left(\mu \mathrm{g} \mathrm{g}^{-1} \text { de folha }\right)\end{array}$ \\
\hline \multirow{4}{*}{$\begin{array}{l}\mathrm{C} 1 \\
\text { (Nov/ } \\
\text { Out/ } \\
2003 \text { ) }\end{array}$} & ENS & $\begin{array}{r}5,63 \pm \\
0,23^{\mathrm{a}}\end{array}$ & $\begin{array}{r}2,74 \pm \\
0,73^{\mathrm{a}}\end{array}$ & $\begin{array}{c}2,06 \pm \\
0,16^{\mathrm{b}}\end{array}$ & $\begin{array}{c}16,11 \pm \\
15,53\end{array}$ & - & - & - & - & - \\
\hline & LAR & $\begin{array}{l}5,44 \pm \\
0,06^{\mathrm{ab}}\end{array}$ & $\begin{array}{l}2,09 \pm \\
0,40^{\mathrm{ab}}\end{array}$ & $\begin{array}{l}1,97 \pm \\
0,25^{\mathrm{b}}\end{array}$ & $\begin{array}{c}13,76 \pm \\
6,49\end{array}$ & - & - & - & - & - \\
\hline & IBV & $\begin{array}{r}5,53 \pm \\
0,14^{\mathrm{a}}\end{array}$ & $\begin{array}{l}2,22 \pm \\
0,39^{\mathrm{ab}}\end{array}$ & $\begin{array}{r}2,47 \pm \\
0,23^{\mathrm{a}}\end{array}$ & $\begin{array}{c}7,86 \pm \\
8,36\end{array}$ & - & - & - & - & - \\
\hline & RDB & $\begin{array}{c}5,29 \pm \\
0,08^{\mathrm{b}} \\
\end{array}$ & $\begin{array}{l}1,95 \pm \\
0,61^{\mathrm{b}} \\
\end{array}$ & $\begin{array}{l}1,97 \pm \\
0,25^{\mathrm{b}} \\
\end{array}$ & $\begin{array}{c}15,84 \pm \\
11,31 \\
\end{array}$ & - & - & - & - & - \\
\hline \multirow{4}{*}{$\begin{array}{l}\text { C2 } \\
\text { (Dez/ } \\
2004)\end{array}$} & ENS & $\begin{array}{c}5,87 \pm \\
0,01\end{array}$ & $\begin{array}{c}4,17 \pm \\
0,89\end{array}$ & $\begin{array}{c}2,24 \pm \\
0,32\end{array}$ & $\begin{array}{c}18,45 \pm \\
23,21\end{array}$ & $\begin{array}{c}185,80 \pm \\
10,37\end{array}$ & $\begin{array}{c}310,43 \pm \\
28,18^{\mathrm{ab}}\end{array}$ & $\begin{array}{c}162,65 \pm \\
16,93^{\mathrm{ab}}\end{array}$ & $\begin{array}{l}1,91 \pm \\
0,05^{\mathrm{ab}}\end{array}$ & $\begin{array}{c}473,08 \pm \\
44,90^{\mathrm{ab}}\end{array}$ \\
\hline & LAR & $\begin{array}{c}5,82 \pm \\
0,14\end{array}$ & $\begin{array}{c}4,41 \pm \\
1,60\end{array}$ & $\begin{array}{c}2,27 \pm \\
0,81\end{array}$ & $\begin{array}{c}16,89 \pm \\
14,90\end{array}$ & $\begin{array}{c}184,43 \pm \\
11,98\end{array}$ & $\begin{array}{c}350,42 \pm \\
74,62^{\mathrm{a}}\end{array}$ & $\begin{array}{c}200,36 \pm \\
60,32^{\mathrm{a}}\end{array}$ & $\begin{array}{l}1,78 \pm \\
0,14^{\mathrm{b}}\end{array}$ & $\begin{array}{c}550,79 \pm \\
134,92^{\mathrm{a}}\end{array}$ \\
\hline & IBV & $\begin{array}{c}5,87 \pm \\
0,08\end{array}$ & $\begin{array}{c}4,89 \pm \\
1,23\end{array}$ & $\begin{array}{c}3,20 \pm \\
0,96\end{array}$ & $\begin{array}{c}8,56 \pm \\
7,29\end{array}$ & $\begin{array}{c}163,14 \pm \\
20,15\end{array}$ & $\begin{array}{c}231,62 \pm \\
47,74^{\mathrm{b}}\end{array}$ & $\begin{array}{c}117,03 \pm \\
26,04^{b}\end{array}$ & $\begin{array}{l}1,98 \pm \\
0,05^{\mathrm{a}}\end{array}$ & $\begin{array}{c}348,66 \pm \\
73,67^{\mathrm{b}}\end{array}$ \\
\hline & $\mathrm{RDB}$ & $\begin{array}{c}5,91 \pm \\
0,18 \\
\end{array}$ & $\begin{array}{c}6,10 \pm \\
1,28 \\
\end{array}$ & $\begin{array}{c}2,81 \pm \\
0,79 \\
\end{array}$ & $\begin{array}{c}50,97 \pm \\
42,46 \\
\end{array}$ & $\begin{array}{c}170,49 \pm \\
18,37 \\
\end{array}$ & $\begin{array}{c}312,87 \pm \\
65,76^{\mathrm{ab}}\end{array}$ & $\begin{array}{c}170,31 \pm \\
43,25^{\mathrm{ab}}\end{array}$ & $\begin{array}{l}1,85 \pm \\
0,09^{\mathrm{ab}} \\
\end{array}$ & $\begin{array}{l}483,18 \pm \\
108,93^{\mathrm{ab}}\end{array}$ \\
\hline \multirow{4}{*}{$\begin{array}{l}\mathrm{C} 3 \\
(\mathrm{Ago} / \\
2005)\end{array}$} & ENS & $\begin{array}{c}5,86 \pm \\
0,13\end{array}$ & $\begin{array}{c}6,37 \pm \\
0,99\end{array}$ & $\begin{array}{r}2,84 \pm \\
0,17^{\mathrm{a}}\end{array}$ & $\begin{array}{c}6,14 \pm \\
2,89\end{array}$ & $\begin{array}{c}173,97 \pm \\
2,35\end{array}$ & $\begin{array}{c}298,03 \pm \\
40,51\end{array}$ & $\begin{array}{c}341,47 \pm \\
55,69\end{array}$ & $\begin{array}{c}0,88 \pm \\
0,03\end{array}$ & $\begin{array}{c}499,32 \pm \\
57,42\end{array}$ \\
\hline & LAR & $\begin{array}{c}6,15 \pm \\
0,14\end{array}$ & $\begin{array}{c}19,03 \pm \\
9,61\end{array}$ & $\begin{array}{r}2,20 \pm \\
0,34^{\mathrm{b}}\end{array}$ & $\begin{array}{c}11,35 \pm \\
8,02\end{array}$ & $\begin{array}{c}177,67 \pm \\
5,71\end{array}$ & $\begin{array}{c}291,60 \pm \\
83,91\end{array}$ & $\begin{array}{c}343,39 \pm \\
107,57\end{array}$ & $\begin{array}{c}0,86 \pm \\
0,03\end{array}$ & $\begin{array}{c}513,81 \pm \\
27,71\end{array}$ \\
\hline & IBV & $\begin{array}{c}5,95 \pm \\
0,32\end{array}$ & $\begin{array}{c}14,97 \pm \\
16,85\end{array}$ & $\begin{array}{r}2,94 \pm \\
0,44^{\mathrm{a}}\end{array}$ & $\begin{array}{c}6,41 \pm \\
3,22\end{array}$ & $\begin{array}{c}172,82 \pm \\
2,77\end{array}$ & $\begin{array}{c}290,92 \pm \\
20,42\end{array}$ & $\begin{array}{c}333,44 \pm \\
25,70\end{array}$ & $\begin{array}{c}0,87 \pm \\
0,01\end{array}$ & $\begin{array}{c}532,78 \pm \\
70,86\end{array}$ \\
\hline & RDB & $\begin{array}{c}6,02 \pm \\
0,10\end{array}$ & $\begin{array}{c}11,84 \pm \\
6,32\end{array}$ & $\begin{array}{l}2,29 \pm \\
0,79^{\mathrm{ab}}\end{array}$ & $\begin{array}{c}9,47 \pm \\
0,34\end{array}$ & $\begin{array}{c}178,77 \pm \\
8,16\end{array}$ & $\begin{array}{c}350,57 \pm \\
23,01\end{array}$ & $\begin{array}{c}419,65 \pm \\
28,44\end{array}$ & $\begin{array}{c}0,83 \pm \\
0,01\end{array}$ & $\begin{array}{c}542,83 \pm \\
68,19\end{array}$ \\
\hline
\end{tabular}

Obs: As letras diferentes (a, b) indicam diferença significativa entre os locais, para cada campanha, ao nível de significância de 10\%. Os conjuntos de dados, onde não constam as letras, não apresentaram diferenças significativas. 
Tabela 2S. Parâmetros bioquímicos da espécie Bauhinia forficata nos locais estudados para cada campanha de coleta de folhas

\begin{tabular}{|c|c|c|c|c|c|c|c|c|c|c|}
\hline $\begin{array}{l}\text { Campanha } \\
\text { de coleta } \\
\text { de folhas }\end{array}$ & Local & $\mathrm{PH}$ & BCI. $\left(10^{-2}\right)$ & $\begin{array}{c}\text { Ácido } \\
\text { Ascórbico } \\
\left(\mathrm{mg} \mathrm{g}^{-1}\right. \\
\text { de folha) }\end{array}$ & $\begin{array}{l}\text { Peroxidase } \\
\text { (U g } \\
\text { de folha) }\end{array}$ & $\begin{array}{c}\beta \text {-caroteno } \\
\left(\mu \mathrm{g} \mathrm{g}^{-1}\right. \\
\text { de folha })\end{array}$ & $\begin{array}{l}\text { Clorofila A } \\
\qquad\left(\mu \mathrm{g} \mathrm{g}^{-1}\right. \\
\text { de folha })\end{array}$ & $\begin{array}{l}\text { Clorofila B } \\
\qquad\left(\mu \mathrm{g} \mathrm{g}^{-1}\right. \\
\text { de folha })\end{array}$ & $\begin{array}{c}\text { Clorofila } \\
\text { A/B }\end{array}$ & $\begin{array}{l}\text { Clorofila Total } \\
\qquad\left(\mu \mathrm{g} \mathrm{g}^{-1}\right. \\
\text { de folha })\end{array}$ \\
\hline \multirow{4}{*}{$\begin{array}{l}\text { C1 (Nov/ } \\
\text { Out/ } \\
2003)\end{array}$} & ENS & $\begin{array}{c}5,66 \pm \\
0,02^{\mathrm{a}}\end{array}$ & $\begin{array}{c}14,31 \pm \\
6,41^{\mathrm{a}}\end{array}$ & $\begin{array}{c}1,03 \pm \\
0,18\end{array}$ & $\begin{array}{c}50,14 \pm \\
24,65\end{array}$ & - & - & - & - & - \\
\hline & LAR & $\begin{array}{c}5,74 \pm \\
0,07^{\mathrm{a}}\end{array}$ & $\begin{array}{l}8,86 \pm \\
2,14^{\mathrm{ab}}\end{array}$ & $\begin{array}{c}0,99 \pm \\
0,15\end{array}$ & $\begin{array}{c}49,47 \pm \\
38,85\end{array}$ & - & - & - & - & - \\
\hline & IBV & $\begin{array}{c}5,46 \pm \\
0,02^{\mathrm{b}}\end{array}$ & $\begin{array}{l}6,06 \pm \\
2,45^{b}\end{array}$ & $\begin{array}{c}0,98 \pm \\
0,11\end{array}$ & $\begin{array}{c}55,10 \pm \\
14,44\end{array}$ & - & - & - & - & - \\
\hline & $\mathrm{RDB}$ & $\begin{array}{c}5,53 \pm \\
0,11^{\mathrm{b}} \\
\end{array}$ & $\begin{array}{l}9,17 \pm \\
5,20^{\mathrm{ab}}\end{array}$ & $\begin{array}{c}1,30 \pm \\
0,50 \\
\end{array}$ & $\begin{array}{c}76,38 \pm \\
7,31 \\
\end{array}$ & - & - & - & - & - \\
\hline \multirow{4}{*}{$\begin{array}{l}\text { C2 (Dez/ } \\
2004)\end{array}$} & ENS & $\begin{array}{c}5,99 \pm \\
0,12^{\mathrm{b}}\end{array}$ & $\begin{array}{c}11,78 \pm \\
5,28^{\mathrm{b}}\end{array}$ & $\begin{array}{c}0,88 \pm \\
0,45\end{array}$ & $\begin{array}{c}50,77 \pm \\
30,91^{\mathrm{b}}\end{array}$ & $\begin{array}{c}204,04 \pm \\
2,96^{\mathrm{b}}\end{array}$ & $\begin{array}{c}512,97 \pm \\
7,60\end{array}$ & $\begin{array}{c}448,47 \pm \\
73,86^{\mathrm{ab}}\end{array}$ & $\begin{array}{c}1,16 \pm \\
0,16\end{array}$ & $\begin{array}{c}961,44 \pm \\
81,45\end{array}$ \\
\hline & LAR & $\begin{array}{c}6,27 \pm \\
0,23^{\mathrm{a}}\end{array}$ & $\begin{array}{c}22,91 \pm \\
4,60^{\mathrm{a}}\end{array}$ & $\begin{array}{c}0,68 \pm \\
0,02\end{array}$ & $\begin{array}{c}130,96 \pm \\
40,14^{\mathrm{a}}\end{array}$ & $\begin{array}{c}195,02 \pm \\
23,49^{\mathrm{b}}\end{array}$ & $\begin{array}{c}464,43 \pm \\
80,77\end{array}$ & $\begin{array}{c}373,81 \pm \\
206,69^{b}\end{array}$ & $\begin{array}{c}1,40 \pm \\
0,56\end{array}$ & $\begin{array}{c}837,99 \pm \\
287,10\end{array}$ \\
\hline & IBV & $\begin{array}{c}5,96 \pm \\
0,06^{\mathrm{b}}\end{array}$ & $\begin{array}{c}13,17 \pm \\
2,62^{\mathrm{ab}}\end{array}$ & $\begin{array}{c}0,72 \pm \\
0,38\end{array}$ & $\begin{array}{c}40,04 \pm \\
30,50^{\mathrm{b}}\end{array}$ & $\begin{array}{c}208,45 \pm \\
16,17^{\mathrm{b}}\end{array}$ & $\begin{array}{c}471,24 \pm \\
86,97\end{array}$ & $\begin{array}{c}434,77 \pm \\
200,62^{\mathrm{b}}\end{array}$ & $\begin{array}{c}1,24 \pm \\
0,50\end{array}$ & $\begin{array}{c}906,02 \pm \\
287,42\end{array}$ \\
\hline & RDB & $\begin{array}{l}6,06 \pm \\
0,16^{\mathrm{ab}}\end{array}$ & $\begin{array}{c}10,01 \pm \\
6,80^{\mathrm{b}} \\
\end{array}$ & $\begin{array}{c}1,08 \pm \\
0,21 \\
\end{array}$ & $\begin{array}{c}50,99 \pm \\
10,88^{\mathrm{b}} \\
\end{array}$ & $\begin{array}{c}234,68 \pm \\
7,44^{\mathrm{a}} \\
\end{array}$ & $\begin{array}{c}519,99 \pm \\
0,71\end{array}$ & $\begin{array}{c}694,92 \pm \\
17,48^{\mathrm{a}} \\
\end{array}$ & $\begin{array}{c}0,75 \pm \\
0,02 \\
\end{array}$ & $\begin{array}{c}1214,91 \pm \\
16,82 \\
\end{array}$ \\
\hline \multirow{4}{*}{$\begin{array}{l}\text { C3 (Ago/ } \\
2005)\end{array}$} & ENS & $\begin{array}{c}6,15 \pm \\
0,07^{\mathrm{a}}\end{array}$ & $\begin{array}{c}30,05 \pm \\
3,29^{\mathrm{ab}}\end{array}$ & $\begin{array}{c}0,30 \pm \\
0,03\end{array}$ & $\begin{array}{c}479,21 \pm \\
138,17^{\mathrm{a}}\end{array}$ & $\begin{array}{c}486,88 \pm \\
147,24\end{array}$ & $\begin{array}{c}169,84 \pm \\
3,74\end{array}$ & $\begin{array}{c}329,48 \pm \\
57,86\end{array}$ & $\begin{array}{c}0,53 \pm \\
0,09\end{array}$ & $\begin{array}{c}639,49 \pm \\
96,20\end{array}$ \\
\hline & LAR & $\begin{array}{c}6,15 \pm \\
0,10^{\mathrm{a}}\end{array}$ & $\begin{array}{c}34,15 \pm \\
7,38^{\mathrm{a}}\end{array}$ & $\begin{array}{c}0,30 \pm \\
0,13\end{array}$ & $\begin{array}{l}180,17 \pm \\
221,78^{\mathrm{b}}\end{array}$ & $\begin{array}{c}508,97 \pm \\
65,53\end{array}$ & $\begin{array}{c}165,97 \pm \\
3,35\end{array}$ & $\begin{array}{c}347,84 \pm \\
25,04\end{array}$ & $\begin{array}{c}0,49 \pm \\
0,03\end{array}$ & $\begin{array}{c}634,99 \pm \\
191,48\end{array}$ \\
\hline & IBV & $\begin{array}{c}6,19 \pm \\
0,10^{\mathrm{a}}\end{array}$ & $\begin{array}{l}36,33 \pm \\
18,82^{\mathrm{ab}}\end{array}$ & $\begin{array}{c}0,36 \pm \\
0,19\end{array}$ & $\begin{array}{c}42,16 \pm \\
9,54^{\mathrm{b}}\end{array}$ & $\begin{array}{c}561,72 \pm \\
194,83\end{array}$ & $\begin{array}{c}179,14 \pm \\
4,48\end{array}$ & $\begin{array}{c}353,63 \pm \\
66,51\end{array}$ & $\begin{array}{c}0,52 \pm \\
0,10\end{array}$ & $\begin{array}{c}624,36 \pm \\
46,08\end{array}$ \\
\hline & RDB & $\begin{array}{c}5,80 \pm \\
0,09^{\mathrm{b}}\end{array}$ & $\begin{array}{c}14,83 \pm \\
6,19^{\mathrm{b}}\end{array}$ & $\begin{array}{c}0,52 \pm \\
0,12\end{array}$ & $\begin{array}{l}27,46 \pm \\
22,42^{\mathrm{b}}\end{array}$ & $\begin{array}{c}584,91 \pm \\
168,88\end{array}$ & $\begin{array}{c}179,73 \pm \\
12,66\end{array}$ & $\begin{array}{c}363,10 \pm \\
55,56\end{array}$ & $\begin{array}{c}0,51 \pm \\
0,06\end{array}$ & $\begin{array}{c}770,22 \pm \\
51,41\end{array}$ \\
\hline
\end{tabular}

Obs: As letras diferentes $(a, b)$ indicam diferença significativa entre os locais, para cada campanha, ao nível de significância de $10 \%$. Os conjuntos de dados, onde não constam as letras, não apresentaram diferenças significativas. 
Tabela 3S. Relação entre as concentrações de poluentes e as alterações bioquímicas nas folhas das espécies vegetais

\begin{tabular}{|c|c|c|c|c|c|c|c|c|}
\hline \multirow[b]{2}{*}{ Campanhas } & \multirow[b]{2}{*}{ Espécies } & \multirow[b]{2}{*}{$\begin{array}{l}\text { Alterações } \\
\text { Bioquímicas }\end{array}$} & \multicolumn{3}{|c|}{ Concentração de ozônio $\left(\mu \mathrm{g} \mathrm{m}^{-3}\right)$} & \multicolumn{3}{|c|}{ Concentração média de outros poluentes $\left(\mu \mathrm{g} \mathrm{m}^{-3}\right)$} \\
\hline & & & $\begin{array}{l}\text { Enseada do } \\
\text { Suá (ENS) }\end{array}$ & $\begin{array}{c}\text { Laranjeiras } \\
\text { (LAR) }\end{array}$ & Ibes (IBV) & $\begin{array}{l}\text { Enseada do } \\
\text { Suá (ENS) }\end{array}$ & $\begin{array}{l}\text { Laranjeiras } \\
\text { (LAR) }\end{array}$ & Ibes (IBV) \\
\hline $\mathrm{C} 1$ & Oiti & $\begin{array}{l}40 \% \text { mais áci- } \\
\text { das em RDB } \\
\text { ácido ascórbico } \\
25 \% \text { maior no } \\
\text { IBV }\end{array}$ & $\begin{array}{l}\text { Out/2003: } \\
\quad 80\end{array}$ & $\begin{array}{l}\text { Out/2003: } \\
\quad 80\end{array}$ & $\begin{array}{c}\text { Out/2003: } \\
120\end{array}$ & $\begin{array}{c}\mathrm{PM}_{10}: 50 \\
\mathrm{SO}_{2}: 30 \\
\mathrm{NO}_{2}: 50\end{array}$ & $\begin{array}{l}\mathrm{PM}_{10}: 60 \\
\mathrm{SO}_{2}: \text { nd } \\
\mathrm{NO}_{2}: 50\end{array}$ & $\begin{array}{c}\mathrm{PM}_{10}: 50 \\
\mathrm{SO}_{2}: 30 \\
\mathrm{NO}_{2}: 40\end{array}$ \\
\hline $\mathrm{C} 2$ & 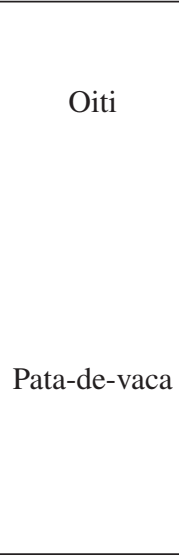 & $\begin{array}{c}\text { clorofila B } \\
30 \% \text { maior e } \\
\text { clorofila A/B } \\
5 \% \text { menor em } \\
\text { LAR } \\
35 \% \text { menos } \\
\text { ácidas, BCI } \\
55 \% \text { maior } \\
\text { e clorofila B } \\
40 \% \text { menor em } \\
\text { LAR } \\
\beta \text {-caroteno } \\
15 \% \text { maior em } \\
\text { RDB } \\
\end{array}$ & $\begin{array}{c}\text { Nov/2004: } \\
80\end{array}$ & $\begin{array}{c}\text { Out/2004: } \\
140\end{array}$ & $\begin{array}{c}\text { Set/2004: } \\
120\end{array}$ & $\begin{array}{l}\mathrm{PM}_{10}: 40 \\
\mathrm{SO}_{2}: 30 \\
\mathrm{NO}_{2}: 50\end{array}$ & $\begin{array}{c}\mathrm{PM}_{10}: 60 \\
\mathrm{SO}_{2}: 25 \\
\mathrm{NO}_{2}: 40\end{array}$ & $\begin{array}{c}\mathrm{PM}_{10}: 40 \\
\mathrm{SO}_{2}: 10 \\
\mathrm{NO}_{2}: 50\end{array}$ \\
\hline $\mathrm{C} 3$ & Oiti & $\begin{array}{c}\text { ácido ascórbico } \\
20 \% \text { maior no } \\
\text { IBV } \\
2 \text { vezes mais } \\
\text { ácidas e BCI } \\
2 \text { vezes maior } \\
\text { em RDB } \\
\text { atividade de } \\
\text { peroxidase } 15 \\
\text { vezes maior na } \\
\text { ENS }\end{array}$ & $\begin{array}{c}\text { Jun/2005: } \\
\quad 60\end{array}$ & $\begin{array}{c}\mathrm{Jul} / 2005: \\
80\end{array}$ & $\begin{array}{c}\mathrm{Jul} / 2005: \\
80\end{array}$ & $\begin{array}{c}\mathrm{PM}_{10}: 50 \\
\mathrm{SO}_{2}: 25 \\
\mathrm{NO}_{2}: 50\end{array}$ & $\begin{array}{c}\mathrm{PM}_{10}: 40 \\
\mathrm{SO}_{2}: 15 \\
\mathrm{NO}_{2}: \mathrm{nd}\end{array}$ & $\begin{array}{c}\mathrm{PM}_{10}: 40 \\
\mathrm{SO}_{2}: 15 \\
\mathrm{NO}_{2}: 50\end{array}$ \\
\hline
\end{tabular}

Obs: nd - não disponível. 